\title{
Nutritional value and pharmacological importance of citrus species grown in Iraq
}

\author{
Dr Ali Esmail Al-Snafi \\ Department of Pharmacology, College of Medicine, Thi qar University, Iraq
}

\begin{abstract}
Citrus fruits contained many phytochemicals including essential oils, alkaloids, flavonoids, coumarins, psoralens, carotenoids with a wide range of nutritional components including vitamins, minerals and trace elements. The previous pharmacological studies revealed that citrus fruits possessed antimicrobial, anthelmintic, insect repellent, antioxidant, anticancer, cardiovascular, central nervous, anti-inflammatory, analgesic, antidiabetic, reproductive, gastrointestinal, immunological, respiratory and many other pharmacological effects. This review was designed to highlight the chemical constituents, nutritional value and pharmacological activities of citrus fruits.
\end{abstract}

Keywords: constituents, nutritiona, pharmacology, citrus fruits, Citrus aurantifolia, Citrus medica, Citrus medica var. limetta, Citrus sinensis

\section{Introduction}

Medicinal plants are the Nature's gift to human beings to help them pursue a disease-free healthy life. Plants are a valuable source of a wide range of secondary metabolites, which are used as pharmaceuticals, agrochemicals, flavours, fragrances, colours, biopesticides and food additives ${ }^{(1-50)}$. Citrus contained nutrients and phytochemicals that were beneficial for health. Citrus fruits and juices contain a wide range of substances including carbohydrates, fibre, vitamin $\mathrm{C}$, potassium, folate, calcium, thiamine, niacin, vitamin B6, vitamin A, phosphorus, magnesium, copper, riboflavin, pantothenic acid and a variety of phytochemicals. These substances are necessary for proper functioning of the body but some confer additional protection against chronic disease over and basic nutrition. Citrus fruits are also low in fat and in overall dietary energy - a major consideration given the increasing rate of obesity in both adults and children. It also has a relatively low glycaemic index which helps in maintaining a more stable blood glucose level and generally healthier carbohydrate metabolism. Citrus fruits also contained many phytochemicals including essential oils, alkaloids, flavonoids, coumarins, psoralens and carotenoids. The previous pharmacological studies revealed that citrus fruits possessed antimicrobial, anthelmintic, insect repellent, antioxidant, anticancer, cardiovascular, central nervous, antiinflammatory, analgesic, antidiabetic, reproductive, gastrointestinal, immunological, respiratory and many other pharmacological effects. This review will highlight the chemical constituents, nutritional value and pharmacological activities of citrus fruits.

\section{Plants profile:} Synonyms ${ }^{(53)}$ :

Any botanical classification of citrus fruit faces several difficulties. All citrus types hybridise easily. New hybrids are continuously developed to obtain desired qualities such as seedlessness, juiciness and fresh taste. New hybrids spontaneously arise by cross-pollination. The most modern methods of molecular research are sometimes needed to distinguish citrus types from each other. However, the synonyms of citrus species were:

\section{Citrus aurantifolia}

Limonia aurantifolia Christre. \& Panzer, Citrus javanica Blume, Citrus notissima Blanco, Citrus acida Roxb., Citrus hystrix ssp. acida (Roxb.) Engl., Citrus lima Lunan, Citrus limetta var. aromatica Wester, Citrus medica var. acida (Roxb.) Hook. f., Limonia aurantiifolia Christm., Citrus acida Pers., Citrus alata (Tanaka) Yu.Tanaka, Citrus amara Link, Citrus articulata Willd. ex Spreng. Citrus assamensis R. M. Dutta \& Bhattacharya, Citrus aurantiaca Swingle, Citrus aurantiifolia var. latifolia Yu. Tanaka, Citrus aurantiifolia subsp. murgetana García Lidón \& al., Citrus aurantium var. amara L., Citrus aurantium subsp. aurantiifolia (Christm.) Guillaumin, Citrus aurantium var. crassa Risso, Citrus aurantium var. daidai Makino, Citrus aurantium var. decumana L. Citrus aurantium f. deliciosa, (Ten.) M. Hiroe, Citrus aurantium f. grandis (L.) M. Hiroe, Citrus aurantium subsp. ichangensis, Citrus aurantium f. intermedia, Citrus aurantium var.japonica, Citrus aurantium subsp.junos, Citrus aurantium var. limetta, Guillaumin. 


\section{Citrus limonum}

Citrus aurantium subsp. bergamia (Risso \& Poit.) Engl., Citrus aurantium subsp. bergamia (Risso) Wight \& Arn., Citrus aurantium var. bergamia (Risso) Brandis, Citrus aurantium var. mellarosa (Risso) Engl., Citrus bergamia Risso \& Poit., Citrus bergamia subsp. mellarosa (Risso) D.Rivera \& al., Citrus bergamota Raf., Citrus limodulcis D.Rivera, Obón \& F.Méndez, Citrus limonelloides Hayata, Citrus limonia Osbeck, Citrus limonia var. digitata Risso, Citrus limonum Risso, Citrus medica var. limon L., Citrus medica f. limon (L.) M.Hiroe, Citrus medica subsp. limonia (Risso) Hook. f., Citrus medica var. limonum (Risso) Brandis, Citrus medica subsp. limonum (Risso) Engl., Citrus medica var. limonum (Risso) Brandis, Citrus mellarosa Risso, Citrus meyeri Yu.Tanaka, Citrus vulgaris Ferrarius ex Mill., Limon vulgaris Ferrarius ex Miller.

\section{Citrus medica}

Aurantium medicum (L.) M. Gómez, Citrus alata (Tanaka) Yu.Tanaka, Citrus alata (Tanaka) Tanaka, Citrus aurantium var. medica (L.) Wight \& Arn., Citrus aurantium var. proper Guillaumin, Citrus aurantium var. tamurana Yu.Tanaka, Citrus balotina Poit. \& Turpin, Citrus bicolor Poit. \& Turpin, Citrus bigena Poit. \& Turpin, Citrus cedra Link, Citrus cedrata Raf., Citrus crassa Hassk., Citrus fragrans Salisb., Citrus gongra Raf., Citrus grandis var. pyriformis (Hassk.) Karaya, Citrus hassaku Yu.Tanaka, Citrus hiroshimana Yu.Tanaka, Citrus kizu Yu. Tanaka, Citrus kwangsiensis Hu, Citrus limetta Risso, Citrus limetta subsp. murcica S.Ríos \& al., Citrus limonia var. limetta (Risso) Engl., Citrus limoni medica Lush., Citrus lumia Risso, Citrus medica var. alata Yu.Tanaka, Citrus medica subsp. Bajoum H. Perrier, Citrus medica var. digitata Risso ex Guillaumin, Citrus medica var. dulcis Risso \& Poit., Citrus medica var. ethrog Engl., Citrus medica var. limetta (Risso) Engl., Citrus medica var. medica, Citrus medica var. nana Wester, Citrus medica var. proper Hook.f., Citrus medica var. sarcodactylus, Citrus medica f. sudachi (Shirai) M.Hiroe, Citrus medica var. tarung Yu.Tanaka, Citrus nana (Wester) Yu.Tanaka, Citrus odorata Roussel, Citrus pyriformis Hassk., Citrus sarcodactylus Siebold ex Hoola van Nooten.

\section{Citrus medica var. limetta}

It is a synonym of Citrus medica L.

Citrus sinensis

Citrus sinensis (L.) Osbeck, Citrus sinensis var. brassiliensis Tanaka, Citrus sinensis subsp. crassa (Risso) D.Rivera \& al., Citrus sinensis subsp. fetifera (Risso) D.Rivera \& al., Citrus sinensis subsp. hierochuntica (Risso) D. Rivera \& al., Citrus sinensis subsp. lusitanica (Risso) D.Rivera \& al., Citrus sinensis var. Sanguinea (Engl.) Engl., Citrus sinensis f. sekkan Hayata, Citrus sinensis var. sekkan Hayata, Citrus sinensis subsp. suntara (Engl.) Engl.

\section{Taxonomic classification:}

Kingdom: Plantae; Subkingdom: Tracheobionta; Superdivision: Spermatophyta; Division: Magnoliophyta; Class: Magnoliopsida; Subclass: Rosidae; Order: Sapindales; Family: Rutaceae; Genus: Citrus $^{(53-54)}$.

Common names ${ }^{(53)}$ :

Citrus aurantiifolia:

Arabic: laimon helo; Chinese: lai meng; English: Egyptian lime, Indian lime, Key lime, lime, Mexican lime, sour lime, lime; French: citron vert, citronnier gallet, lime acid, limettier, limettier des Antilles, limettier mexicain; German: Limette, Limettenbaum, Limone, saure Limette; India: kagzi nimboo, kagzi nimbu; Italian: lima; Portuguese: limão-galego, limão-tahiti; Spanish: limón agrio, limón ceutí, lima, lima mejicana, limero.

\section{Citrus limonum}

Arabic: laimon hamidh; Chinese: li meng, ning meng; English: lemon; French: Citronnier, lemonier; German; Zitrone; Italian: limone; Portuguese: Limão, limoeiro-azedo, limão-eureka, limão-gênova, limão-siciliano, limão-verdadeiro, limoeiro; Spanish: limón, limonero.

Citrus medica

Arabic: Raranj, Trunj; Chinese: fo shou gan, xiang yuan; English: Buddha's-Hand, citron, etrog citron, finger citron flesh-finger citron, small citron; French; cédrat, cédratier, main de Bouddha, sarcodactyle; German: Buddhafinger, gefingerte Zitrone, medischer Apfel, Zitronatzitrone; Italian: cedrato; Japanese: bushukan; Portuguese: cidra, cidreira; Spanish: cidro; toronja; Swedish: etrogcitron, fingercitron, suckatcitron.

\section{Citrus medica var limetta}

Arabic: noomi helo, laimon helo; English: Mediterranean limetta, Mediterranean lumia, Mediterranean sweet lemon, Sweet lemon, Sweet lime; French: Limette à mamelon, Limette d'Italie, Limette douce de Tunisie, Limettier à fruits doux, Limettier doux, Limonette; German:: Süße Zitrone; Italian: Limetta, Limetta, dolce 
romana Limoncella patriarca; Japanese: Suiito remon, Rimetta, Rimetta oodineeru. Portuguese: Lima de bico; Spanish: Limeta dulce de Túnez, Limón dulce, Limonero dulce.

Citrus sinensis:

Arabic: Burtaqal; Chinese: tian cheng English: blood orange, navel orange, orange, sweet orange, Valencia orange; French: Navel, orange douce, oranger, oranger doux, sanguine; German: Apfelsine, Apfelsinenbaum, Orange, Orangenbaum; Italian: arancio dolce; Portuguese: laranja-doce, laranjeira, laranjeira-doce, laranjaamarga, laranja-azeda, laranja-bigarade, laranja-da- terra, laranja -de-sevilha; Spanish: naranja, naranjo duce.

\section{Distribution:}

The primitive center of origin of citrus species has been a subject of speculation and discussion for some time. The most recent research indicates an origin in Australia, New Caledonia and New Guinea. Some researchers believe that the origin is in the part of Southeast Asia bordered by Northeast India, Burma (Myanmar) and the Yunnan province of China ${ }^{(3-4)}$. Now, a worldwide cultivation and highdemand production for citrus fruit make it stand high among fruit crops. Growth of the citrus industry, including rapid development of the processing technology of frozen concentrated orange juice after World War II, has greatly expanded with international trade and steadily increased consumption of citrus fruits and their products during the past several decades. Because of distinct aroma and delicious taste, citrus fruits have been recognized as an important food and integrated as part of our daily diet, playing key roles in supplying energy and nutrients and in health promotion. Citrus fruits are characterized by low protein and very little fat content, citrus fruits supply mainly carbohydrates, such as sucrose, glucose, and fructose. Fresh citrus fruits are also a good source of dietary fiber, which is associated with gastrointestinal disease prevention and lowered circulating cholesterol. In addition to vitamin $\mathrm{C}$, which is the most abundant nutrient, the fruits are a source of $\mathrm{B}$ vitamins (thiamin, pyridoxine, niacin, riboflavin, pantothenic acid, and folate), and contribute phytochemicals such as carotenoids, flavonoids, and limonoids. These biological constituents are of vital importance in human health improvement due to their antioxidant properties, ability to be converted to vitamin A (for example, $\beta$ cryptoxanthin), and purported protection from various chronic diseases. All these characteristics enhanced worldwide citrus fruit cultivation ${ }^{(53)}$.

\section{Traditional uses:}

\section{Citrus aurantifolia}

Citrus aurantifolia was used traditionally as laxative, appetizer, stomachic, digestive, anthelmintic, dyspepsia, flatulence and helmenthiasis ${ }^{(55)}$. Citrus aurantifolia was also used for cold fevers, sore throats, sinusitis and bronchitis, as well as helping asthma. Its oil is mainly used as antidepressant because it promoted refreshment to the tide mind. It can be helpful for rheumatism arthritis, obesity and has an astringent and toning action to clear oily skin and acne, in the treatment of herpes, cuts and insect bites ${ }^{(56-57)}$.

\section{Citrus limonum}

Lemon juice is widely known as diuretic, antiscorbutic, astringent, and febrifuge. In Italy, the sweetened juice is given to relieve gingivitis, stomatitis, and inflammation of the tongue. Lemon juice in hot water has been widely advocated as a daily laxative and preventive of the common cold, but daily doses have been found to erode the enamel of the teeth. Prolonged use will reduce the teeth to the level of the gums. Lemon juice and honey, or lemon juice with salt or ginger, is taken as a cold remedy ${ }^{(58)}$.

\section{Citrus medica}

In traditional medicine, ripe fruits were used in sore throat, cough, asthma, thirst, hiccough, earache, nausea, vomiting, anti scorbutic, stomachic, tonic, stimulant, expellant of poison, correct fetid breath; distilled water of the fruit was sedative, fruits and seeds were cardiac tonic and used in palpitation, fruit decoction is analgesic. Roots, flowers, seeds, peels and leaves were used in many ailments. The fruit wrapped in cloth was used to protect clothes from moths indicating its insect repellent activity. In ancient literature, citron was mentioned as an antidote for various kinds of poison ${ }^{(58-62)}$.

\section{Citrus medica var limetta}

Citrus medica var limetta fruit and leaves were used for healing of common cold, control of blood lipids, for the treatment of fever, regulation of inflammatory and digestive disorders and as a blood pressure modulator ${ }^{63-}$ 64)

\section{Citrus sinensis}

Oranges were eaten to allay fever and catarrh. The roasted pulp was prepared as a poultice for skin diseases. An infusion of the immature fruit was taken to relieve stomach and intestinal complaints. The flowers were employed medicinally by the Chinese people living in Malaya. Orange flower water, made in Italy and 
France as antispasmodic and sedative. A decoction of the dried leaves and flowers was given in Italy as an antispasmodic, cardiac sedative, antiemetic, digestive and remedy for flatulence. The inner bark, macerated and infused in wine, was taken as a tonic and carminative. Decoction of husked orange seeds was prescribed for urinary ailments in China and the juice of fresh orange leaves or a decoction of the dried leaves was taken as a carminative or emmenagogue or applied on sores and ulcers. An orange seed extract was given as a treatment for malaria in Ecuador but it was known to cause respiratory depression and a strong contraction of the spleen $^{(58,65)}$.

\section{Description:}

Tree growth and form varies depending on the species and genetic background and whether the tree was established by seed or grafting. Trees produced from seed tend to have more thorns and upright branch growth than trees produced from grafting.

Flowers are $2-4 \mathrm{~cm}(0.8-1.6$ in) in diameter, axillary, fragrant, single, few or cymose, and often perfect (having both functional stamens and pistils) or staminate. The calyx is 4-5 lobed and there are usually five petals with oil glands. Stamens number between 20 and 40. Petal colors range from white to pinkish in Kafr lime to pinkish to purplish externally in citron and reddish in lemon varieties. The subglobose ovary is superior, with 8-18 locules (cavities), with 4-8 ovules per locule in two rows.

Leaves are entire, 4 to $8 \mathrm{~cm}$ (1.6-3.2 in) in length, unifoliate, fairly thick, with winged petioles. Leaves are ovate, oval or elliptical, with acute to obtuse tips, and glands containing oils in glands, which are released when crushed. Young twigs are angled in cross-section, green, and axillary single-spined, while older twigs and branches are circular in cross-section and spineless.

The fruit is a hesperidium, a feshy, indehiscent berry that ranges widely in size, color, shape, and juice quality. Citrus fruit range in size from $4 \mathrm{~cm}(1.6$ in) for lime to over $25 \mathrm{~cm}$ (10 in) in diameter for pummelo. Fruits are globose to ovoid in shape. The feshy endocarp is divided into 10-14 sections containing the stalked pulp and separated by thin septa. Each section contains pulp (juice vesicles) that contains a sour or sweetish watery juice.

Seeds are pale whitish to greenish, fattened, and angular. The seeds are usually polyembryonic, meaning they have multiple embryos that can germinate. The embryos are either (zygotic) or (nucellar). The zygotic embryos are derived from pollination of the ovary, sexual reproduction. The nucellar embryos are derived wholly from the mother plant and display very similar characteristics to the parent plant $^{(66-68)}$.

\section{Chemical constituents:}

Citrus essential oils were obtained from the citrus fruits peel's sacks. They were used by the food industry to give flavor to drinks and foods. They were also used in the pharmaceutical industry for the preparation of drugs, soaps, perfumes and other cosmetics as well as for home cleaning products ${ }^{(69-70)}$. The pericarp (rind) of Citrus aurantiifolia contained 7 percent essential oil. The major compounds were Dlimonene, D-dihydrocarvone, verbena, $\beta$-linalool, $\alpha$-terpinol, trans- $\alpha$-bergamotene, citral, fenchon , as well as terpineol, bisabolene, and other terpenoids ${ }^{(71-72)}$. However, a total of 46 compounds were identified from the Citrus aurantiifolia oil. Most of these were terpenes, which were found in greater amounts than sesquiterpenes, aldehydes, ketones, phenols, and free acids. Alcohols and some terpenes show higher percentage areas in the maturity stages. D-limonene showed a concentration level higher than $70 \%$, followed by bergamol (8\%), $\beta$-pinene $(7.62 \%)$, linalool $(2.89 \%)$, $\alpha$-pinene $(0.82 \%)$. The isolated compounds were included, $\alpha$-Pinene, Camphene, $\beta$-Pinene, Sabinene, $\beta$-Myrcene, d-Limonene, Nonanal, (Z) Sabinene hydrate, Nonane, Undecanal, Linalool, Camphor, Bergamol, Trans- $\alpha$-bergamotene, Aromadendrene, Terpinen-4-ol, Epi- $\beta$-santalene, Trans-sabinene hydrate, Farnesol, Isopinocarveol, Terpineol acetate, $\alpha$-Terpineol, Neryl acetate, Neral, Geranyl acetate, Geranial, Cis-geraniol, 1-Cyclohexen-1, -methanol 4-1 methylenil acetate, Octal cyclopropene, Cis-myrtanol, Perillal, 2-Tridecen-1-ol, 3-Cyclohexen-1-ol, Cyclohexyl-dodecane, Bicyclo $(2,2,1)$ Heptane, 2,2diethyl-3-methyl P-menth-1-en-8-ol, $\beta$-Bisabolol, Carveol, $\alpha$-Farnesene, $\alpha$-Bisabolol, $\beta$-Farnesene, Trans- $\beta$-santalol, $\alpha$-Santalol, Isopropyl palmitate, $\beta$-Santalene and Cyclopropamethanol ${ }^{(73)}$.

Constituents of leaf essential oil of Citrus medica L. and their percentage were:

Limonene 18.36, 7-Oxabicyclo[4.1.0] heptane, 1-methyl-4-(1-methylethenyl)- 1.18, 6-Octenal, 3,7dimethyl- 4.39 Cyclohexanone, 2-methyl-5-(1-methylethenyl)- 2.24, 1-Monolinoleoylglycerol trimethylsilyl ether 0.86, 6-Octen-1-ol, 3,7-dimethyl- 1.72, n-pentyl(1-propenyl)dimethylsilane 0.82, citral 12.95, 2-Octen1-ol, 3,7-dimethyl-, isobutyrate, (Z)- 1.10, 2-Oxocycloheptyl acetate 0.87, 2,4-Dodecadienoic acid, 11 methoxy-3,7,11-trimethyl-, methyl ester, (E,E)- 1.22, Methoprene 3.51, Geranyl methyl ether 1.42, 13 Heptadecyn-1-ol 1.05, 1,2-Cyclohexanediol, 1-methyl-4-(1-methylethenyl)- 3.98, 2,6-Octadien-1-ol, 3,7dimethyl-, acetate, (Z)- 5.23, Mehp 8.96, 3,7-Nonadien-2-ol, 4,8-dimethyl- 1.16, Erucylamide 28.43. While, the constituents of peel essential oil of Citrus medica L. and their percentage were: (1R)-2,6,6- 
Trimethylbicyclo[3.1.1]hept-2-ene $0.14, \quad \alpha$-Pinene $0.41, \quad 3$-Octyn-2-ol $0.10, \quad \beta$-Myrcene 2.70, 2-Acetyl-5methylfuran 0.05, Cyclooctyl alcohol 0.17, Limonene 21.78, Isolimonene 39.37, 1,3,6-Octatriene, 3,7dimethyl-, (Z)- 0.43, 1-Heptanol, 3-methyl- 0.04, Linalool 0.94, Nonanal 0.25, trans-p-Mentha-2,8-dienol 0.04, 7-Oxabicyclo[4.1.0]heptane, 1-methyl-4-(1-methylethenyl)- 0.41, citral 23.12, 6-Octenal, 3,7-dimethyl0.29, cis-Verbenol 0.09, Carane, 4,5-epoxy-, trans 0.30, 1,2-Cyclohexanediol, 1-methyl-4-(1-methylethyl)0.03 , 4-Terpineol 0.08, Terpinyl acetate $0.16, \beta$-Terpinyl acetate 0.52 , Decanal 0.33 , Neryl acetate 2.51, Neryl Alcohol 2.25, Undecanal 0.10, Neryl acetate 0.60, Dodecanal 0.08, (Z,E)- $\alpha$-Farnesene 0.05, Caryophyllene $0.59, \quad \alpha$-Bergamotene $0.48, \quad$ 1,6,10-Dodecatriene, 7,11-dimethyl-3-methylene-, $(\mathrm{Z})$ - 0.04 , Tetrakis(trimethylsiloxy)silane 0.04, $\alpha$-Caryophyllene 0.08, Germacrene D 0.05, cis-. $\alpha$-Bisabolene 0.07, $\gamma$ Elemene 0.05, $\beta$-Bisabolene 0.71, $\delta$-Cadinene 0.05, Tetradecanal 0.10, Neoisolongifolane, hydroxy- $0.07, \beta$ Bisabolol 0.12 and n-Hexadecanoic acid $0.12^{(74)}$. The volatile fraction of every sample of Citrus medica oil characterized by a high content of limonene, $\gamma$-terpinene, and monoterpene aldehydes and a lower content of $\alpha$ and $\beta$-pinene and myrcene, sesquiterpenes, and aliphatic aldehydes. GC analysis of the extracts allowed the determination of the enantiomeric distribution of five terpenoid compounds; a prevalence of four dextrorotatory isomers was observed. Oxypeucedanin was the main component of the oxygenated heterocyclic fraction in the extracts of green fruits, while citropten was the major oxygenated compound in the oil obtained from yellow citron $^{(75)}$.

Eleven constituents were identified from Citrus limonum leaves essential oils. Citronellal ( 29.31 $\%)$, limonene (17.59\%), (E)-citral (12.71\%), 1,6-octadien-3-ol,3,7- dimethyl (10.91\%), biocyclo [3.1.0] hexane, 4-mehylene-1-(1-methyl) (8.80\%), 6-octen-1-ol,3,7-dimethl (7.95\%), 2,6-octadien-1-ol,3,7-dimethyl-, acetate, (Z) (6.29 \%), 1,3-cyclohexadiene,5-(1,5-dimethyl-4-hexenyl)-2-methyl, [S(R,S)] (2.81 \%), cyclohexene,3-(1,5-dimethyl-4-hexenyl)-6-methylene-, [S-(R,S)](1.64\%), bezene,1-(1,5-dimethyl-4-hexenyl)4-methyl (1.10\%) and cyclohexene,1-methyl-4-(5-methyl-1-methyl-1-methylene-4-hexenyl)-,(s) $(0.88 \%)^{(75-77)}$.

Hydro distillation of the peels of Citrus limetta yielded $0.313 \%$ oil. Gas chromatographic analysis identified 17 constituents among which limonene (95.98\%) was found as major component followed by camphene $(1.79 \%)$, while the remaining terpenes were less than $1 \%$. However, the chemical composition of essential oil of Citrus limetta and their percentage were: $\alpha$-hujene $0.0688, \alpha$-pinene, 0.0381, $\beta$-pinene 0.0299, $\rho$-cymene 0.3861, Camphene 1.7865, Limonene 95.9768, $\alpha$-terpinene, 0.3337, Neral 0.2907, Geraniol 0.3641, Geranial 0.0315, Citronellal 0.0951, $\alpha$ - terpinol, 0.3191, $\alpha$-humulene, $0.0511, \beta$-bisabolene 0.1276 and $\beta$-sinesol $0.0268^{(78-80)}$

Citrus sinensis fruit contains $1.5 \%$ essential oil. The components of fruit peel of Citrus sinensis and their percentage were: Octane $8.37,4$-Methylthiazole $0.14, n$-Nonane $0.2, \alpha$-Pinene 6.65, Sabinene 6.50, Myrcene 17.55, $n$-Octanal 0.19, $\alpha$-Phellandrene 0.33, iso-Sylvesteren 1.14, Limonene 61.34, E- $\beta$-Ocimene 0.5, $\gamma$-Terpinene 0.5, Linalool 1.84, $\alpha$-Thujene 2.31, trans-Limonene oxide 0.18, Citronellal 0.29, Decanal $1.40, \beta$-Elemene 0.08, Tetradecane $0.21, \quad \beta$-Caryophyllene 0.1 , Valencene 0.48 , Pentadecane 0.2 and Hexadecane $0.2^{(80-81)}$.

Nutritional analysis of Citrus aurantifolia, Citrus limonum, Citrus sinensis and Citrus medica (per 100g of edible portion) showed that they contained: moisture: $84.6,85.0,88.4,87.1 \mathrm{~g}$, protein: $1.5,1.0,0.8,0.081 \mathrm{~g}$, fat: $1,0.9,0.3,0.04 \mathrm{~g}$, fiber: $1.3,1.7,0.5,1.1 \mathrm{~g}$, carbohydrates: $10.9,11.1,9.3,6.9 \mathrm{~g}$, minerals:0.7, 0.3, 0.7, 0.3 g, Iron: $0.3,2.3,0.7,0.55 \mathrm{mg}$, Carotene 15,0, 0, $0.009 \mu \mathrm{g}$, and Energy, 59,57, 43 and 30 Kcal respectively ${ }^{(58,69,82)}$.

Phytochemical analysis showed that Citrus aurantifolia, Citrus limonum and Citrus sinensis fruits contained: alkaloids: $0.33 \pm 0.11,0.54 \pm 0.20,0.62 \pm 0.10$; flavonoids: $0.29 \pm 0.20,0.57 \pm 0.10,0.19 \pm 0.20$; tannins: $0.04 \pm 0.11,0.01 \pm 0.10,0.04 \pm 0.11$; phenols: $0.02 \pm 0.10,0.05 \pm 0.11,0.01 \pm 0.10$; and saponins: 0.22 $\pm 0.30,0.42 \pm 0.10,0.08 \pm 0.10 \mathrm{mg} / 100 \mathrm{~g}$ dry weight respectively ${ }^{(69,83)}$.

Citrus flavonoids, coumarins, psoralens and carotenoids composition were:

Citrus sinensis flavonoids: [Flavanones (Didymin 1.89\%, Eriocitrin $0.31 \%$, Hesperidin 28.6\%, Narirutin $5.2 \%$ ); Flavones (Neoeriocitrin 0.59\%, Poncirin 1.04\%, 6,8-di-C-Glu-Apigenin 5.72\%, 6,8-di-C-GluDiosmetin $\quad 0.35 \%$, Rhoifolin $0.05 \%$, Isorhoifolin $0.07 \%$, Diosmin $0.09 \%$, Neodiosmin 0.08\%); Polymethoxyflavones (Heptamethoxyflavone $0.08 \%$, Nobiletin $0.33 \%$, Sinensetin $0.37 \%$, Tangeretin $0.04 \%$ ) and Aglycones( Taxifolin 0.03\%, Acacetin 0.03\%)]. Coumarins and psoralens: (auraptenol, scoparon, xanthyletin). carotenoids: (Phytoene, phytofluene, $\beta$-carotene, $\beta$-carotene, cryptoxanthin, lutein, antheraxanthin, mutatoxanthins, violaxanthin, luteoxanthins, auroxanthins).

Citrus limon flavonoids: [Flavanones (Eriocitrin 16.7\%, Hesperidin 20.5\%); Flavones (6,8-di-C-GluApigenin1.17\%, 6,8-di-C-Glu-Diosmetin 4.95\%, 7-O-Rut-Luteolin 3.93\%, Diosmin 3.12\%), Aglycones (Luteolin 0.08\%)].Coumarins and psoralens: (Bergapten, bergamottin, byakangelicin, citropten, imperatorin, isoimperatorin, isopimpinellin, phellopterin, prangol, scoparon, scopoletin, umbelliferone, umbelliprenin, xanthyletin). Carotenoids: (Phytofluene, $\beta$-carotene, cryptoxanthin, violaxanthin, auroxanthin). 
Citrus medica flavonoids: (hesperidin, eriocitrin, rutin and diosmin and naringin). Coumarins and psoralens: (citrumedin-B, bergapten and citropten). Citrus medica also contained 5-methoxy furfural, 5-hydroxy-2hydroxymethyl-4H-pyran-4-one, diosmetin, diosmin, obacunone, aviprin, 3-(3-methoxy-4-hydroxyphenyl)acrylic acid, vanillic acid and 3,4-dihydroxy-benzoic acid.

Citrus limmeta flavonoids: (hespiridin, naringin). However, peels of Citrus limmeta contained eighty-five compounds, including three abscisic acid derivatives, five limonoid glycosides, twenty-six dihydro-cinnamic and cinnamic acid glycosides, eleven flavanone glycosides, seven flavone glycosides, seventeen flavonol glycosides, including limocitrol and limocitrin derivatives.

Citrus aurantifolia flavonoids: [Flavanones (Eriocitrin $0.29 \%$, Hesperidin $1.77 \%$, Neoeriocitrin $0.01 \%$ ); Flavones (Diosmin 0.08\%), Polymethoxyflavones (Heptamethoxyflavone $0.12 \%$, Natsudaidain $0.04 \%$, Nobiletin $0.52 \%$, Tangeretin 0.18\%); Aglycones (Taxifolin $0.04 \%$, Luteolin 0.61\%) ${ }^{(69,84-89)}$.

The favonoids contents of Citrus juice were included: Flavonoid composition of Citrus aurantifolia juice $(\mathrm{mg} / 100 \mathrm{ml})$ : Flavanones (Eriocitrin 0.29, Hesperidin 1.77, Neoeriocitrin 0.01); Flavones (Diosmin 0.08); Polymethoxyflavones (Heptamethoxyflavone 0.12, Natsudaidain 0.04, Nobiletin 0.52,Tangeretin 0.18); Aglycones (Taxifolin 0.04, Luteolin 0.61). Flavonoid composition of Citrus limon juice (mg/100 ml): Flavanones (Eriocitrin16.7, Hesperidin 20.5); Flavones ( 6,8-di- $C$-Glu-Apigenin 1.17, 6,8-di- $C$-Glu-Diosmetin 4.95, 7-O-Rut-Luteolin 3.93, Diosmin 3.12); Aglycones (Luteolin 0.08). Flavonoid composition of Citrus sinensis juice (mg/100 ml): Flavanones ( Didymin 1.89, Eriocitrin 0.31, Hesperidin 28.6, Narirutin 5.2); Flavones (Neoeriocitrin 0.59, Poncirin 1.04, 6,8-di-C-Glu-Apigenin 5.72, 6,8-di-C-Glu-Diosmetin 0.35, Rhoifolin 0.05, Isorhoifolin 0.07, Diosmin 0.09, Neodiosmin 0.08); Polymethoxyflavones (Heptamethoxyflavone 0.08, Nobiletin 0.33, Sinensetin 0.37, angeretin 0.04); Aglycones (Taxifolin 0.03, Acacetin 0.03$)^{(34)}$.

Flavonoid content of Citrus aurantifolia roots, stem, stem bark, leaves and peels were 0.64 \pm 0.40 , $0.33 \pm 0.01,0.42 \pm 0.01,0.06 \pm 0.07$ and $0.51 \pm 0.02 \%$ respectively. While, the flavonoid content of Citrus limon roots, stem, stem bark, leaves and peels were $0.60 \pm 0.01,0.34 \pm 0.02,0.47 \pm 0.01,0.65 \pm 0.03$ and $0.48 \pm 0.01 \%$ respectively. Citrus sinensis roots, stem, stem bark, leaves and peels showed $0.63 \pm 0.01,0.29 \pm 0.01,0.38 \pm 0.05$, $0.63 \pm 0.03$ and $0.35 \pm 0.01 \%$ flavonoids content respectively ${ }^{(90)}$.

Although pectin occurs in a majority of plant cell walls, it was most abundant in citrus (lime, lemon, grapefruit, and orange) fruits. The structure of pectin was primarily composed of repeating units of galacturonic acid joined by a $1 \rightarrow 4$ glycosidic linkages, which create a linear polymer. The regular linear structure was interrupted by the presence of neutral sugar side chains. Furthermore, the carboxyl groups of galacturonic acid may either remain as free acids, be esterified with methanol, or be neutralized with cations. The chemical structure of pectin varies by fruit species and also during the different developmental stages of the fruit ${ }^{(91)}$.

Mineral contents of Citrus aurantifolia, Citrus limonum and Citrus sinensis were: phosphorus $0.29,0.38,0.41$; potassium $1.0,0.37,0.82$; magnesium $0.36,0.33,0.33$; sodium $0.36,0.33,0.33$ and calcium $2.81,2.0$ and $0.2 \mathrm{~g} / 100 \mathrm{~g}$ respectively ${ }^{(83)}$.

Vitamin contents of Citrus aurantifolia, Citrus limonum, Citrus sinensis and C. medica fruits were: ascorbic acid: $22.88,61.60,19.36,368$; thiamin: 0.11, 0.88, 0.06, 0.052; riboflavin: 0.04, 0.02,0.11, 0.029 and niacin: $0.03,0.14,0.38$ and $0.125 \mathrm{mg} / 100 \mathrm{~g}$ respectively ${ }^{(58,82-83)}$.

In citrus species, limonoids, limonoids were produced in leaves and transported to fruit and seeds, with limonoid concentration highest in the earliest stages of growth of leaves and fruit and highest in seeds during fruit growth and maturation. In leaves and fruit, total limonoid content increases during growth and maturation and decreases after maturation. In contrast, limonoid concentration does not decrease in seeds after fruit maturity, indicating that seeds act as storage tissues for these compounds ${ }^{(92)}$.

Although pectin occurs in a majority of plant cell walls, it was most abundant in citrus (lime, lemon, grapefruit, and orange) fruits. The pectin was composed of repeating units of galacturonic acid joined by a $1 \rightarrow$ 4 glycosidic linkages, which create a linear polymer. The regular linear structure is interrupted by the presence of neutral sugar side chains. Furthermore, the carboxyl groups of galacturonic acid may either remain as free acids, be esterified with methanol, or be neutralized with cations. The chemical structure of pectin varies by fruit species and also during the different developmental stages of the fruit ${ }^{(91)}$.

Organic acid contents of Citrus aurantifolia, Citrus limonum and Citrus sinensis juices were: oxalic acid: 0.109, 0.094, 0.110; tartaric acid 0.336, 0.073, 0.012; malic acid 1.516, 1.465, 5.183; lactic acid: 1.857, 1.545, 0.915 ; citric acid 13.918, 73.936, 61.497 and ascorbic acid $0.636,0.718$ and $0.354 \mathrm{~g} / 1$ respectively $^{(93)}$.

\section{Pharmacological effects:}

Citrus fruits, are one of the main fruit tree crops grown throughout the world. Although sweet orange (Citrus sinensis) is the major fruit in this group accounting for about $70 \%$ of citrus output. The group also encompasses other citrus fruits such as Citrus reticulata, Citrus vitis, Citrus aurantifolia, Citrus medica and Citrus limonum ${ }^{(69)}$. 


\section{Antimicrobial effect:}

The antibacterial potential of the leaf essential oil and petroleum ether, chloroform, ethyl acetate and methanol extracts of the leaves of Citrus aurantifolia were studied against human pathogenic bacteria (Bacillus cereus, Enterobacter faecalis, Salmonella paratyphi, Staphylococcus aureus, Escherichia coli, Proteus vulgaris, Klebsiella pneumoniae, Pseudomonas aeruginosa and Serratia marcescens) by agar well diffusion method. Leaf essential oil as well as ethyl acetate, chloroform and methanol extracts of Citrus aurantifolia leaves exhibited pronounced activity against Gram-positive and Gram-negative bacteria and their activity was quite comparable with the standard antibiotics such as tobramycin, gentamicin sulphate, ofloxacin and ciprofloxacin screened under similar conditions ${ }^{(94)}$.

Studying of the antibacterial effect of varieties of citrus available in Malaysian (Citrus aurantifolia, Citrus reticulata, Citrus microcarpa, Citrus limon and Citrus sinensis) against Streptococcus pyogenes, Staphylococcus aureus, Escherichia coli and Pseudomonas aeruginosa showed that the methanol extract of the five varieties of citrus exerted no inhibition at 5 and $10 \mathrm{mg} / \mathrm{ml}$. The methanol extract of Citrus microcarpa, Citrus reticulata and Citrus sinensis at $20 \mathrm{mg} / \mathrm{ml}$ showed better inhibition compare to Citrus aurantifolia and Citrus limon against Staphylococcus aureus and Escherichia coli ${ }^{(95)}$.

Citrus sinensis, Citrus limon, and Citrus aurantifolia fruit peel extracts were investigated against gastrointestinal pathogens. Citrus aurantifolia and Citrus limon showed high zone of inhibition against Shigella Spp., and E. coli strains. Whereas Citrus aurantifolia was effective against Salmonella Spp $^{(96)}$.

The antimicrobial potency of Citrus aurantifolia was studied against many bacterial and fungal pathogenes, in the different forms [juice of the fruit, burnt rind of the fruit commonly known as (epa-ijebu) in the Yoruba dialect, and the oil obtained from steam distillation of the fruit]. Antimicrobial activity was carried out by the agar well diffusion. The clinical isolates used included Anaerobic facultative bacteria, namely: Staphylococcus aureus ATCC 25213, Staphylococcus aureus, Salmonella paratyphi, Shigella flexnerii, Streptococcus faecalis, Citrobacter spp, Serratia spp, Klebsiella pneumoniae, Pseudomonas aeruginosa, Escherichia coli ATCC 25922, and Escherichia coli; Fungi such as Aspergilus niger and Candida albicans; and Anaerobes which includes Bacteroides spp, Porphyromonas spp, and Clostridium spp. Crude extracts of all solvents used varied in zones of inhibition. The anaerobes and the Gram-positive bacteria were susceptible to all the extracts with minimum inhibitory concentration (MIC) ranging from $32 \mathrm{mg} / \mathrm{ml}-128 \mathrm{~g} / \mathrm{ml}$. The antifungal study showed that only the oil extract was potent against $A$. niger, while Candida albicans was susceptible to all the extracts with MIC ranging from $256 \mathrm{mg} / \mathrm{ml}-512 \mathrm{mg} / \mathrm{ml}$. The Gram-negatives showed MIC ranging from $64 \mathrm{mg} / \mathrm{ml}-512 \mathrm{mg} / \mathrm{ml}$. Minimum bactericidal concentration (MBC) ranged between $32 \mathrm{mg} / \mathrm{ml}$ to $512 \mathrm{mg} / \mathrm{ml}$ depending on isolates and extracting solvent. The oil and palm-wine extract showed greater activity than the other extracts ${ }^{(97)}$.

The antimicrobial efficacy of leaf extract of Citrus aurantifolia Linn (CA) was evaluated against some microorganisms - bacteria and fungus (Staphylococcus aureus, Escherichia coli, Klebsiella pneumonia, Pseudomonas spp, Aspergillus niger, Aspergillus fumigates, Mucor Spp and Pencillium Spp). $100 \mu \mathrm{of} 10 \mathrm{mg}$ CA were assessed against eight test microorganisms by agar well diffusion method. A different solvent was used to obtain CA leaf extract using maceration technique. Due to its high yield value, hydroalcoholic extract of CA was used for estimating the antimicrobial activity. The study demonstrates that the hydroalcoholic extract of CA leaf exhibit antibacterial activity on Klebsiella pneumonia, Pseudomonas sp, Staphylococcus aureus and antifungal activity among Aspergillus niger, Aspergillus fumigates and Mucor species $^{(98)}$.

Citric acid extracted from Citrus aurantifolia was tested as antimicrobial agent. The largest inhibition area of citric acid was obtained against Escherichia coli, $3.92 \mathrm{~cm}$, and the smallest inhibition area is obtained against Lactobacillus acidophilus, $2.16 \mathrm{~cm}^{(99)}$.

Citrus aurantifolia oils were tested against Mycobacterium tuberculosis. The saturated fatty acid palmitic acid exhibited higher activity against multidrug-resistant $M$. tuberculosis strains (MICs $=50 \mu \mathrm{g} / \mathrm{ml}$ ) than the unsaturated fatty acids oleic acid and linoleic acid, which showed less activity (MICs $=100 \mu \mathrm{g} / \mathrm{ml})^{(100)}$. The antibacterial activity of Lemon, lime and sudachi juices was studied against seven strains of Vibrio species. All juices were effective in inhibiting the growth of the Vibrio strains. Citric acid, the major organic acid in these juices, were found to be responsible for inhibiting the growth of Vibrio parahaemolyticus, whereas the sauce adjusted to higher $\mathrm{pH}$ values had no bacterial activity. Diluted sudachi juice or citric acid solution also had antibacterial activity independently. The results suggest that citrus fruit juices were effective in preventing infection with Vibrio species ${ }^{(101)}$.

The effect of essential oils, natural and concentrated lemon juice and fresh and dehydrated lemon peel was studied against $V$. cholerae $\mathrm{O} 1$ biotype Eltor serotype Inaba tox+. Products were used at different dilutions, when $V$. cholerae present at concentrations of $10^{2}, 10^{4}, 10^{6}$ and $10^{8}$ colony forming units (CFU) $/ \mathrm{ml}$, and after different exposure times. Concentrated lemon juice and essential oils inhibited V. cholerae completely at all studied dilutions and exposure times. Fresh lemon peel and dehydrated lemon peel partially inhibited growth of $V$. cholerae. Freshly squeezed lemon juice, diluted to $10^{-2}$, showed complete inhibition of $V$. cholerae at a concentration of $10^{8} \mathrm{CFU} / \mathrm{ml}$ after $5 \mathrm{~min}$ of exposure time; a dilution of $2 \times 10^{-3}$ produced inhibition after 15 min and a dilution of $10^{-3}$ after $30 \min ^{(102)}$. 
The antibacterial activity of crude extracts (aqueous and ethanolic) of Citrus limonum fruits against four wound isolates Staphylococcus sp, Pseudomonas sp, Escherichia coli and Klebsiella sp. showed that they exerted antibacterial activity with diameter of inhibition zone of 20,18, 20 and $15 \mathrm{~mm}$ for ethanolic extract, and 15, 20, 11, and $10 \mathrm{~mm}$ for aqueous extract respectively ${ }^{(103)}$.

The potential inhibitory effect of Citrus lemon and Citrus sinensis on lipophilic, yeast like fungus Malassezia furfur which causes Pityriasis versicolor, chronic superficial fungal disease of the skin have been studied using two different methods (Disc diffusion and microdilution methods). In screening of lemon and orange oil by disc diffusion method, the diameters of inhibition zone were found to be 50 and $20 \mathrm{~mm}$ which were greater than inhibition zone of reference antibiotics, gentamycin $16.5 \mathrm{~mm}$ and streptomycin $17 \mathrm{~mm}$. Minimum inhibitory concentrations (MIC) of lemon and orange oil against $M$. furfur were found to be 0.8 and $2.2 \mu 1 / \mathrm{ml}^{(104)}$.

The antimicrobial activity of Citrus lemon was studied in vitro. The citrus peel oils show strong antimicrobial activity. The antimicrobial activity has been checked in terms of MIC by using different solvents against microorganisms like Pseudomonas aeruginosa NCIM 2036 for which MIC was 1:20 by methanol extract, for Salmonella typhimurium NCIM 5021 the observed MIC was 1:20 by acetone extract. While, for Micrococcus aureus NCIM 5021 the observed MIC was 1:20 by ethanol extract ${ }^{(105)}$.

The antimicrobial activity of different types and parts of lemon was evaluated against different microbial isolates. The antimicrobial effects of aqueous extracts of peel and juice from fresh and dried citrus and sweet lemon were evaluated against 6 Gram-positive and 8 Gram-negative bacterial and one yeast isolates, including Staphylococcus aureus, Staphylococcus epidermidis, Streptococcus pyogenes, Enterococcus faecalis, Streptococcus pneumoniae, Streptococcus agalactiae, Pseudomonas aeruginosa, Enterobacter aerogenes, Klebsiella pneumoniae, Escherichia coli, Salmonella typhi, Proteus spp., Moraxella catarrhalis, Acinetobacter spp. and Candida albicans. The water extracts of all the materials showed various inhibitory effects. The juice of Citrus limon has antimicrobial activities more than other types of extracts. Escherichia coli, Staphylococcus epidermidis, Streptococcus agalactiae and Candida albicans showed the highest resistance to these extracts. Lemon species might have antimicrobial activity against different Gram-positive, Gram-negative and yeast pathogens and could be used for prevention of various diseases caused by these organisms ${ }^{(106)}$.

The effects of Citrus limonum essential oils (EO) compared to $0.2 \%$ chlorhexidine (CHX) and $1 \%$ sodium hypochlorite $(\mathrm{NaOCl})$ was studied in multispecies biofilms formed by Candida albicans, Enterococcus faecalis and Escherichia coli. The biofilms were grown in acrylic disks immersed in broth, inoculated with microbial suspension (106 cells $/ \mathrm{ml}$ ) and incubated at $37^{\circ} \mathrm{C} / 48 \mathrm{~h}$. After the biofilms were formed, they were exposed for 5 minutes to the solutions: Citrus limonum EO, $0.2 \% \mathrm{CHX}, 1 \% \mathrm{NaOCl}$ or sterile saline solution. The discs were placed in sterile $0.9 \% \mathrm{NaCl}$ and sonicated to disperse the biofilms. Tenfold serial dilutions were performed and the aliquots were seeded onto selective agar and incubated at 37C / $48 \mathrm{~h}$. Next, the number of colony-forming units per milliliter was counted and analyzed statistically (Tukey test, $\mathrm{p}<0.05$ ). Citrus limonum EO promoted a $100 \%$ reduction of $C$. albicans and E. coli, and $49.3 \%$ of $E$. faecalis. CHX was less effective against $C$. albicans and $E$. coli, yielding a reduction of $68.8 \%$ and $86.7 \%$, respectively. However, the reduction of E. faecalis using $\mathrm{CHX}(81.7 \%)$ was greater than that obtained using Citrus limonum EO. Citrus limonum EO was effective in controlling multi-species biofilms; the microbial reductions achieved by EO were not only similar to those of $\mathrm{NaOCl}$, but even higher than those achieved by $\mathrm{CHX}$, in some cases ${ }^{(107)}$.

The antibacterial activity of Citrus limon was studied against Acne vulgaris. Citrus limon juice was used at different concentrations of $(20 \%, 40 \%, 60 \%, 80 \%$ and $100 \%)$ on Propioni bacterium acne. The Citrus limon juice was found to be effective at all concentrations used ${ }^{(108)}$.

Essential oil from the fresh leaf of Citrus medica L. var. sarcodactylis possessed strong antimicrobial activity against Staphylococcus aureus and Bacillus subtilis (MIC 2,500 ppm). However, the antimicrobial efficiency of essential oil from this plant was much lower (about 40\%) than that of tetracycline solution at the same concentration ${ }^{(109)}$.

The antibacterial effect of the peels of Citrus medica was evaluated on Staphylococcus aureus MTCC96, Escherichia coli MTCC739, Proteus vulgaris MTCC426, Bacillus subtilis MTCC441, Klebsiella pneumonia MTCC109 and Pseudomonas aeruginosa MTCC424. The solvent used for the extraction of plants was water ethanol. The in vitro antibacterial activity was performed by agar cup method. The most susceptible Gram-positive bacteria were Staphylococcus aureus while the most susceptible Gram-negative bacteria was Klebsiella pneumonia and Pseudomonas aeruginosa. The antibacterial activity of active extract was compared with the standard antibiotic, streptomycin $(100 \mathrm{ppm})^{(110)}$.

Antimicrobial activity of fruit juice and ethanolic extracts of root, leaf, bark, peel and pulp of Citrus medica were examined against seven bacteria (Bacillus subtilis, Staphylococcus aureus, Enterococcus faecalis, Escherichia coli, Klebsiella pneumoniae, Pseudomonas aeruginosa and Proteus vulgaris), two fungi (Aspergillus flavus and A. niger) and a yeast Candida albicans of clinical origin. The antimicrobial effects were studied using an in vitro disc diffusion method; minimum inhibitory concentrations (MIC) and minimum bactericidal concentrations (MBC) were determined by standard agar dilution method. All extracts and fruit juice showed varied level of antibacterial activity against one or more test bacteria. Root, leaf and bark extracts 
inhibited S. aureus, E. faecalis and $P$. vulgaris with maximum inhibition by root extract comparable to standard antibiotic. Fruit peels have shown least activity among all extracts and slightly inhibited growth of $S$. aureus, K. pneumoniae and $P$. vulgaris. The yeast $C$. albicans was not inhibited by any extract. Among bacteria $S$. aureus and $P$. vulgaris were highly susceptible to all extracts while B. subtilis was highly resistant and inhibited by only fruit juice. Root extract had the lowest MIC $0.5 \mathrm{mg} / \mathrm{ml}$ and MBC $1 \mathrm{mg} / \mathrm{ml}$ against $S$. aureus. The maximum MIC of extracts was $50 \mathrm{mg} / \mathrm{ml}$ and MBC $75 \mathrm{mg} / \mathrm{ml}$. The minimum MIC of juice was < $1 \%$ and $\mathrm{MBC} 1 \%$ against $\mathrm{P}$. vulgaris while maximum MIC was $3.5 \%$ and $\mathrm{MBC} 7 \%$. Antifungal activity was shown by only root extract and fruit juice while C. albicans was resistant to all tested samples ${ }^{(111)}$.

The antimicrobial activity against the selected bacteria and fungi was observed for the alcoholic extract of Citrus medica, it was found active against all the tested bacteria and fungi (Enterobacter aerogenes, Staphylococcus aureus,Bacillus subtilis, Proteus vulgaris, Klebsiella pneumoniae, Shigella flexneri, Chryseobacterium gleum and fungi Candida albicans, Aspergillus niger and Aspergillus flavus). The maximum antibacterial activity was shown against Staphylococcus aureus $(6.3 \mathrm{~mm})$ by methanolic extract, whereas the maximum antifungal activity was shown against A. niger $(6.3 \mathrm{~mm})$ and minimum activity was shown against A. flavus $(3 \mathrm{~mm})^{(112)}$.

The antibacterial investigation of crude extracts (aqueous and ethanolic) of fruits of Citrus medica var limetta against four wound isolates Staphylococcus sp, Pseudomonas sp, Escherichia coli and Klebsiella sp., showed that they exert antibacterial activity with diameter of inhibition zone of 10, 12, 10 and $10 \mathrm{~mm}$ for ethanolic extract, and 8, 9, 8 and $9 \mathrm{~mm}$ for aqueous extract respectively ${ }^{(113)}$.

The aqueous extract of the peels of $C$. limetta produced a good antimicrobial activity against 15 isolates, Staphylococcus aureus, Staphylococcus epidermidis, Streptococcus pyogenes, Enterococcus faecalis, Streptococcus pneumoniae, Streptococcus agalactiae, Pseudomonas aeruginosa, Enterobacter aerogenes, Klebsiella pneumoniae, Escherichia coli, Salmonella typhi, Proteus spp., Moraxella catarrhalis, Acinetobacter spp. and Candida albicans, with inhibition zones ranged (from 10 to 35mm) against Gram-positive or Gramnegative bacteria with no activity against Candida $^{(106)}$.

The results of antimicrobial activity of peel essential oil of Citrus limetta var. Mitha tested by disc diffusion method, against different against bacteria and fungi showed that it exhibited maximum zone of inhibition against Bacillus cereus ATCC $14579(28 \mathrm{~mm})$ and Bacillus subtilis ATCC 6633 (26 mm) followed by Staphylococcus aureus ATCC $25923(21 \mathrm{~mm})$, whereas the minimum zone of inhibition was shown by Fusarium oxysporum ATCC $48122(11 \mathrm{~mm})$ after $48 \mathrm{~h}$ of incubation at their respective temperature $\left(37^{\circ} \mathrm{C}\right.$ for bacteria and $25^{\circ} \mathrm{C}$ for fungi). The inhibition zones, measured after 48 and $96 \mathrm{~h}$, showed that it was active against all the tested bacteria and fungi ${ }^{(79)}$.

The anti typhoid activity of aqueous extract of fruit peel Citrus sinensis was studied in vitro. The aqueous extracts of fruit peel Citrus sinensis exhibited antityphoid activity against Salmonella typhi, Salmonella paratyphi A and Salmonella paratyphi $\mathrm{B}^{(113)}$.

The antibacterial activity of aqueous and ethanol extracts of Citrus sinensis leaves was evaluated aginst Escherichia coli, Pseudomonas aeruginosa, Klebsiella pneumoniae, and Staphylococcus aureus. The in vitro antibacterial activity was performed by agar disc diffusion method. The aqueous extract showed a zone of inhibition against Escherichia coli $(7 \mathrm{~mm})$, while on the other organisms it showed little or no zones of inhibition ranging from $0-3 \mathrm{~mm}$ in diameter. The ethanol extract also showed little zones of inhibition against the tested organisms ranging from $1-3 \mathrm{~mm}$ in diameter ${ }^{(114)}$.

The peels were air-dried and ground to powder, extracted with $95 \%$ ethanol. The extract was subjected to antibacterial study against six Salmonella paratyphi B, one Salmonella typhi and three Aeromonas hydrophila. Agar diffusion method was employed to test the antibacterial activity of the extract and the MIC and MBC of the extract were determined by broth dilution technique. The results showed that the isolates were sensitive to the extract, with MIC of $0.25-2.5 \mathrm{mg} / \mathrm{ml}$ and $\mathrm{MBC}$ of $0.5-5.0 \mathrm{mg} / \mathrm{ml}^{(115)}$.

Peels of Citrus lemon, Citrus sinensis and Citrus limetta were dried and extracted by cold water, hot water, methanol, ethanol, ethyl acetate and acetone. Extracts were subjected to antibacterial and antifungal susceptibility assay against (Pseudomonas aeruginosa, Salmonella typhimurium, Micrococcus aureus, Trichophyton mentagrophytes, Microsporum canis and Candida albicans) by agar well diffusion method. All the extracts of Citrus lemon were found to be effective against the tested bacterial pathogens except hexane extracts. Methanol and acetone extract showed maximum zone of inhibition of $18 \mathrm{~mm}$. Only methanol extract was effective against fungal pathogens showing a zone of inhibition of $18 \mathrm{~mm}$. Hexane extract of Citrus sinensis was found to be most effective against bacterial pathogens giving a zone of $13 \mathrm{~mm}$. Only the cold water extract of orange was effective against fungal pathogens. Acetone extract of Citrus limetta was most effective giving a zone of $20 \mathrm{~mm}$ against bacterial pathogens. Only cold water and ethyl acetate extracts of Citrus limetta were effective against fungal pathogens giving a zone of inhibition of $17 \mathrm{~mm}$ and $15 \mathrm{~mm}$ respectively ${ }^{(116)}$.

The antimicrobial activity of methanolic extract of $C$. sinensis fruit peel was tested against three bacterial and two fungal strains using turbidimetric or tube dilution method and paper disc diffusion method. C. sinensis fruit peel methanolic extract exhibited antibacterial activity against Escherichia coli with minimum inhibitory 
concentration of $0.78 \mu \mathrm{g} / \mathrm{ml}$ and minimum bactericidal concentration of $6.25 \mu \mathrm{g} / \mathrm{ml}$, and appreciable antifungal activity with minimum inhibitory concentration of $12.5 \mu \mathrm{g} / \mathrm{ml}^{(117)}$. The dried peels of Citrus sinensis were defated and then were subjected to the methanolic extraction. The methanolic extract obtained was dissolved in various solvents such as water, methanol, ethanol, chloroform, diethyl ether and were subjected to evaluation of antitubercular activity against Mycobacterium tuberculosis by Microplate Alamar Blue Assay (MABA) method. The results concluded that the extract dissolved in water as solvent showed significant activity at $50 \mu \mathrm{gm} / \mathrm{ml}{ }^{(118)}$. The antimicrobial activity of petroleum ether extract of the peels of Citrus sinensis was studied against various Gram positive organisms (Staphylococcus epidermidis, Micrococcus luteus, Bacillus subtilis), Gram negative organisms (Escherichia coli, Pseudomonas vulgaris, Salmonella typhi), and fungal strains (Aspergillus niger, and Candida albicans). Antimicrobial activity was conducted by the agar well diffusion method. The extract showed various levels of antimicrobial activity on the tested microorganisms. It was more effective against Staphylococcus epidermidis, Micrococcus luteus and Pseudomonas vulgaris followed by Salmonella typhi, Escherichia coli and Candida albicans, while it showed no activity against Bacillus subtilis and Aspergillus niger ${ }^{(119)}$.

The antmicrobial effects of aqueous extracts of peel, juice and leaves from fresh Citrus sinensis was evaluated against 3 Gram-positive and 6 Gram-negative bacterial, including S. aureus, S. pyogenes, E. feacalis, P. aeruginosa, K. pneumoniae, E. coli, S. typhi, Proteus spp., M. catarrhalis. Citrus juices showed the highest antibacterial activity against most of the studied bacterial isolates. Moderate activity produced by the citrus peels and the lowest effect was produced by the extract of the citrus leaves ${ }^{(120)}$.

The antimicrobial activity of Citrus sinensis oil was studied by paper disc diffusion method against Bacillus subtilis and Escherichia coli. Zones of inhibition of E. coli and B. subtilis were 13 and $17 \mathrm{~mm}$ respectively $^{(121)}$.

The antimicrobial potential and the minimum inhibitory concentration (MIC) of aqueous and ethanol (cold and hot) extracts of Citrus sinensis peel extracts was investigated against Aggregatibacter actinomycetemcomitans, Porphyromonas gingivalis and Prevotella intermedia, using agar well diffusion method. The results showed that Prevotella intermedia and Porphyromonas gingivalis were resistant to aqueous extracts while Aggregatibacter actinomycetemcomitans was inhibited at very high concentrations. Hot ethanolic extracts showed significantly higher zone of inhibition than cold ethanolic extract. Minimum inhibitory concentration of hot and cold ethanolic extracts of Citrus sinensis peel ranged between 12-15 mg/ml against all three periodontal pathogens ${ }^{(122)}$.

Citrus aurantifolia juice destroyed human immunodeficiency virus (HIV). Ten percent of Citrus aurantifolia juice produced a 1000-fold reduction in HIV activity in a laboratory sample ${ }^{(123)}$.

To evaluate the effect of extracts of peels of Citrus sinensis $(\mathrm{Cs})$ on the replication of coronavirus $(\mathrm{CoV})$ and on the expression of TRP genes during coronavirus infection, HeLa-CEACAM1a (HeLa-epithelial carcinoembryonic antigen-related cell adhesion molecule 1a) cells were inoculated with MHV-A59 (mouse hepatitis virus-A59) at moi of 30. 1/50 dilution of the extracts was found to be the safe active dose. ELISA kits were used to detect the human IL-8 levels. Total RNA was isolated from the infected cells and cDNA was synthesized. Fluidigm Dynamic Array nanofluidic chip 96.96 was used to analyze the mRNA expression of 21 TRP genes and two control genes. Data was analyzed using the BioMark digital array software. Determinations of relative gene expression values were carried out by using the $2(-\Delta \Delta \mathrm{Ct})$ method (normalized threshold cycle $(\mathrm{Ct})$ value of sample minus normalized $\mathrm{Ct}$ value of control). TCID50/ml (tissue culture infectious dose that will produce cytopathic effect in $50 \%$ of the inoculated tissue culture cells) was found for treatments to determine the viral loads. TRPA1, TRPC4, TRPM6, TRPM7, TRPM8 and TRPV4 were the genes which expression levels changed significantly after Cs extract treatments. The virus load decreased when Cs extracts was added to the CoV infected cells. Extract treatment had an effect on IL-8 secretion, TRP gene expression and virus load after CoV infection ${ }^{(124)}$.

\section{Anthelmintic and repellent effects:}

Methanolic extract of Citrus medica was evaluated for anthelmintic activity against Indian adult earthworm Pheritima posthuma. Various concentrations of extract were tested and results were expressed in terms of time for paralysis and time for death of worms. Piperazine citrate $(10 \mathrm{mg} / \mathrm{ml})$ was used as a reference standard and distilled water as a control group. Dose dependent anthelmintic activity was possessed by the methanolic extract of Citrus medica ${ }^{(125)}$.

Petroleum ether extracts of Citrus medica leaves also possessed dose dependant anthelmintic activity against the Indian adult earthworms (Pheretima posthumad). The effect which could be attributed to inhibition of glucose uptake in the parasites and depletion of its glycogen synthesis. It also activated nicotinic cholinergic receptor in the worms resulting in either persistent depolarization or hyperpolarization ${ }^{(126)}$.

The anthelmintic activity of petroleum ether extract of the peels of Citrus sinensis was studied against Indian adult earthworms, Pheretima posthuma, it exhibited a dose dependent inhibition of spontaneous motility (paralysis), and evoked responses to pin-prick, and the effects were comparable with that of piperazine 
citrate $^{(119)}$.The effect of aqueous extract of this Citrus medica on viability of the protoscolices of Echinococcus granulosus in vitro, in a concentration of $90 \mathrm{mg} / \mathrm{ml}$, the aqueous extract was effective in killing all protoscolices after four days of incubation ${ }^{(127)}$.

Alcoholic extracts of the rind of Citrus medica showed in vitro anthelmintic activity against human Ascaris lumbricoides ${ }^{(128)}$.The larvicidal potential of hexane and petroleum ether extracts of Citrus limetta peels was assessed against dengue fever vector, Aedes aegypti, and malarial vector, Anopheles stephensi, by evaluating the toxicity effects on early fourth instars. Both the extracts were found effective against both the species. The bioassay with hexane extracts resulted in $\mathrm{LC}_{50}$ values of 132.45 and $96.15 \mathrm{ppm}$ against A. stephensi and A. aegypti, respectively; while the petroleum ether extracts from the $C$. limetta peels showed $\mathrm{LC}_{50}$ values of 244.59 and $145.50 \mathrm{ppm}$, respectively. It revealed that the hexane extracts possessed 1.9-fold more larvicidal potential against $A$. stephensi and 1.5-fold more efficacy against $A$. aegypti as compared to the extracts obtained using petroleum ether as solvent. The data further revealed that the extracts were 1.4-1.7 times more effective against A. aegypti as compared to A. stephensi ${ }^{(129)}$.

The mosquito repellent activity of extracts from Peels of five citrus fruit species, Citrus sinensis, Citrus limonum, Citrus aurantifolia, Citrus reticulata and Citrus vitis, were studied using five different concentrations, $5 \%, 10 \%, 15 \%, 20 \%$ and $25 \%$ (volume by volume). Topical application of the extract concentrations on human volunteers revealed that $20 \%$ and $25 \%$ repelled mosquitoes 2 hours and 5 hours, respectively. Short-lived and mild skin itching and sneezing reactions were observed as side effects ${ }^{(130)}$.

\section{Antioxidant effect:}

The DPPH radical scavenging activities of the leaf extracts and leaf essential oil of Citrus aurantifolia were investigated on 1, 1- diphenyl-2-picrylhydrazyl (DPPH) radical. Among the leaf extracts and leaf essential oil of $C$. aurantifolia studied, leaf methanol and ethyl acetate extracts showed potent scavenging activity ${ }^{(94)}$.

The antioxidant effects of fresh juice and peel extract of Citrus aurantifolia was evaluated. $5 \mu l$ of lime juice didn't change LDL oxidation. $10 \mu \mathrm{l}$ of juice inhibited LDL oxidation, and with increasing the juice concentration, LDL was oxidized faster. Both juice and peel demonstrated antioxidant properties ${ }^{(131)}$.

The antioxidant properties of Citrus aurantifolia peel and leaves from different areas were studied using the diphenyl picryl hydrazyl, 2,2'-azino-bis(3-ethyl benzo thiazoline-6-sulfonic acid) and ferric reducing ability of plasma assays, and the $\beta$-carotene bleaching test. Methanol extracts of the peel and leaves demonstrated the strongest radical scavenging activity. A similar trend was observed with the reducing ability, with values from 112.1 to $146.0 \mu \mathrm{mol} / 1 \mathrm{Fe} / \mathrm{g}{ }^{(87)}$.

The in vitro antioxidant activities of juices of both unripen and ripen Citrus aurantifolia was investigated. Juices were extracted from fresh ripen and unripen fruits by mechanical squeezing and were used for antioxidant study. The antioxidant activity of juice was evaluated by using the free radical scavenging activity of 1, 1-diphenyl-2-picrylhydrazyl radical (DPPH), total antioxidant capacity (TAC) by the phosphomolybdenum method. Unripen juices showed more antioxidant scavenging activity as compared to ripen juices. The lower antioxidant activity of ripe fruit juices could be due to the possible reduction in the ascorbic acid and total phenolic content during ripening. The unripe juice showed a range of 3.45 to $28.23 \%$ at 25 to $200 \mu \mathrm{l}$ concentrations respectively. At the same concentration range the value for the ripe juice was found to be 2.08 to $23.56 \%$ respectively. The total antioxidant content in terms of ascorbic acid ( $\mathrm{mg} / \mathrm{ml})$ was 0.178 and $0.127 \mathrm{mg} / \mathrm{ml}$ for unripe and ripen juices respectively ${ }^{(132)}$.

Various in vitro and ex vivo studies were performed to estimate the polyphenols and flavonoids in the Citrus limonum pulp and peel. The reducing power, free radical scavenging activity and lipid peroxide inhibition were also investigated. The lemon peel was found to have a slightly greater contents of polyphenols and flavonoids. The peel extracts also showed better reducing power and higher free radical scavenging activity. The peel extracts gave $82.3 \%$ of inhibition towards lipid peroxidation, when compared to the pulp extracts which showed an inhibition of $78.2 \%^{(133)}$.

Citrus limon essential oil (EO) showed strong antioxidant activity in mice. Furthermore, it also possessed scavenger activity in all in vitro tests ${ }^{(134)}$.Essential oil of Citrus limon leaves reduced the lipid peroxidation and nitrite content as well as increase the glutathione reduced (GSH) levels and enzymatic antioxidant activities (super-oxide dismutase, catalase and glutathione peroxidase) in mice hippocampus. These findings strongly support the hypothesis that oxidative stress in hippocampus might occur during neurodegenerative diseases, proving that hippocampal damage induced by the oxidative process played a crucial role in brain disorders, which implies that a neuroprotective effect could be achieved using Citrus limon essential oil as antioxidant treatment ${ }^{(135)}$. The action of Citrus limonum essential oil to control free radicalinduced lipid peroxidation and preventing tissue damage in skin was investigated. The superoxide anion scavenging activity of essential oil was evaluated by the enzymatic hypoxanthine/xanthine oxidase system. The same oil diluted in DMSO or grape-seed oil was spread on the face of human volunteers after UV exposition. A sample of skin lipids was collected and the presence of peroxyl radicals was detected based on the measurement of light emitted (chemiluminescence) when the excited carbonyl and singlet oxygen decay to ground state. Data 
demonstrated that the lemon essential oil was more active than $\alpha$ - tocopherol against $\mathrm{O}^{2}$ - and peroxide free radical inhibition at 1:100 dilution ${ }^{(136)}$. The antioxidant activity of $70 \%$ aqueous methanol extract of the defatted powdered leaves of Citrus medica was calculated to be $102.9 \mu \mathrm{g} / \mathrm{ml}$. It also exerted significant reduction in blood glucose level to $(105.2 \pm 8.35)$ in diabetic rats after one month of treatment with a dose of 200 $\mathrm{mg} / \mathrm{kg}$ and to $(87.4 \pm 6.30)$ with $400 \mathrm{mg}$. The authors concluded that the methanol extract of the defatted powdered leaves of Citrus medica exhibited significant antihyperglycemic activity which might be attributed to the presence of flavonoid compounds ${ }^{(137)}$.The extract of Citrus medica showed significant antioxidant activity verified by different assays (DPPH test, $\beta$-carotene bleaching test and bovine brain peroxidation assay) in a dose dependent manner as compared to ascorbic acid ${ }^{(138-139)}$.

The antioxidant potential of ethanolic extract of Citrus medica L. peels (ECMP) extract was studied on Thiobarbituric Acid Reactive Substances (TBARS) as index of lipid peroxidation and on the glycemic control in streptozotocin induced diabetic rats. ECMP was used in as (200 and $400 \mathrm{mg} / \mathrm{kg})$. The elevated level of blood glucose, glycosylated hemoglobin, TBARS observed in diabetic rats were significantly decreased after treatment with ECMP for 8 weeks in diabetic rats. From the results, the ethanolic extract of Citrus medica L. peels possessed potent antioxidant and antidiabetic properties ${ }^{(140)}$.

The results of antioxidant activity of peel essential oil of Citrus limetta var. Mitha showed that it was able to reduce the stable radical 1- diphenyl-2-picrylhydrazyl (DPPH) to yellow-colored DPPH-H reaching $87.77 \%$ of DPPH scavenging effect at its $100 \%$ concentration comparative to ascorbic acid as reference standard being a strong antioxidant reagent ${ }^{(79)}$.

The in vitro antioxidant activity of the methanol extracts of Citrus limetta fruit peel (MECL) was evaluated in different models such as DPPH, superoxide radical and nitric oxide radical scavenging activity and inhibition of lipid peroxidation. The total phenolic compounds present in the extracts were estimated by FolinCiocalteu's reagent. The extract showed good free radical scavenging activity in a dose dependent manner. The $\mathrm{IC}_{50}$ values for $\mathrm{DPPH}$, superoxide radical, nitric oxide radical inhibition and lipid peroxidation assays of MECL were 7.36, 9.36, 136.45 and 111 respectively. Measurement of total phenolic compounds by Folin- Ciocalteu's reagent indicated that $1 \mathrm{mg}$ extract contains $126.85 \mu \mathrm{g}$ equivalent of pyrocatechol in MECL ${ }^{(141)}$.

Extracts prepared from the Citrus limetta fruit peels were studied for antioxidant and anti- inflammatory activity using in vitro bioassays. Among all extracts, ethanol extract of Citrus limetta fruit peels has shown promising anti-oxidant and anti-inflammatory activity ${ }^{(142)}$.

It was reported that juice and edible parts of Citrus sinensis of different origin and from different varieties exerted antioxidant activity, while, the peel extracts were found to have a good total radical antioxidative potential $^{(143-144)}$. Methanolic extracts of 6 citrus species $(C$. sinensis var. Washington Navel, $C$. sinensis var. Valencia, $C$. reticulata var. Page, $C$. sinensis var. Sungin, $C$. paradise and $C$. aurantium) peels and tissues growing in Pakistan were investigated for their antioxidant activity by DPPH method. IC 50 for antioxidant activity ranged from $0.8-4.7 \mathrm{mg} / \mathrm{ml}$. Total phenolic content of the citrus spp. samples (based on folin Ciocalteu method) varied from 99.4 to $229.5 \mathrm{mg}$ gallic acid equivalent/g of extract and flavonoids content (based on colorimetric $\mathrm{AlCl}_{3}$ method) varied from 0.2 to $25.7 \mathrm{mg}$ quercetin equivalent/g of extract. There were no correlation between the total phenolic and/ or flavonoids contents and antioxidant activity in tissues and/or peels ${ }^{(145)}$.

The in vitro antioxidant activity of Citrus sinensis peel extracts from different solvents were investigated. Among the different solvent extracts methonolic extract exhibited the highest in vitro scavenging activity followed by other solvent extracts which includes ethanolic, hexane, benzene, ethyl acetate, and chloroform with $\mathrm{IC}_{50}$ values $65.44,120,138.45,151.34,170.34,185.35$ with $55.6 \%$ inhibitory concentration for ascorbic $\operatorname{acid}^{(146)}$.

Hesperidin was extracted from the peel of Citrus sinensis, and its antioxidant capacity was evaluated. Hesperidin was found to be moderately active as an antioxidant agent; its capacity reached $36 \%{ }^{(147)}$.

The antioxidant, protective and bioavailability of Citrus sinensis juice (poly)phenols were studied by monitoring urinary flavanone metabolites and ring fission catabolites produced by the action of the colonic microbiota. Twelve volunteers [6 men and 6 women; body mass index (in $\mathrm{kg} / \mathrm{m}^{2}$ ): 23.9-37.2] consumed a low (poly)phenol diet for 2 days before first drinking $250 \mathrm{ml}$ pulp-enriched orange juice, which contained $584 \mu \mathrm{mol}$ (poly)phenols of which $537 \mu \mathrm{mol}$ were flavanones. Urine collected for a $24-\mathrm{h}$ period was analyzed qualitatively and quantitatively. A total of 14 metabolites were identified and quantified in urine after orange juice intake. Hesperetin-O-glucuronides, naringenin-O-glucuronides, and hesperetin-3'-O-sulfate were the main metabolites. The overall urinary excretion of flavanone metabolites corresponded to $16 \%$ of the intake of $584 \mu \mathrm{mol}$ (poly)phenols. This bioavailability could be explain the antioxidant and protective effect of orange juice (poly)phenols ${ }^{(148)}$.

\section{Cardiovascular effects:}

According to World Health Organization's recent report, citrus fruits offer protection against cardiovascular diseases by reducing levels of homocysteine. Orange fruit contained vitamin C, carotenoids and 
flavonoids, which were cardio- protective. Cholesterol lowering effect of orange was produced by limonene. Furthermore, polymethoxylated flavones (PMFs) were present in citrus fruit peel, which can lower cholesterol more effectively than some prescription drugs, without showing any side effect. Although, a variety of citrus fruits contain PMFs, the most common PMFs were tangeretin and nobiletin. PMFs work like statin drugs that inhibit the synthesis of cholesterol and triglycerides inside the liver. However, a tablespoon or so of the peel of orange each day, may be a practical way of achieving some cholesterol-lowering benefits ${ }^{(149)}$.

Hesperidin, a bioflavonoid, was an abundant and inexpensive by-product of citrus cultivation. A deficiency of this substance in the diet has been linked with abnormal capillary leakiness as well as pain in the extremities causing aches, weakness and night leg cramps. No signs of toxicity have been observed with the normal intake of hesperidin or related compounds ${ }^{(150)}$.

The effect of drinking the juice of two different citrus fruits on vascular neointima formation was studied using a cuff-induced vascular injury mouse model. Male C57BL6 mice were divided into five groups as follows: 1) Control (water) (C), 2) 10\% citrus unshiu (CU) juice (CU10), 3) 40\% CU juice (CU40), 4) $10 \%$ citrus iyo (CI) juice (CI10), and 5) 40\% CI juice (CI40). After drinking them for 2 weeks from 8 weeks of age, cuff injury was induced by polyethylene cuff placement around the femoral artery. Neointima formation was significantly attenuated in CU40, CI10 and CI40 compared with C. However, no remarkable preventive effect was observed in CU10. The increases in levels of various inflammatory markers including cytokines such as monocyte chemotactic protein-1, interleukin-6 (IL-6), IL-1 $\beta$, and tumor necrosis factor- $\alpha$ in response to vascular injury did not differ significantly between C, CU10 and CI10. The increases in cell proliferation and superoxide anion production were markedly attenuated in CI10, but not in CU10 compared with C. The increase in phosphorylated ERK expression was markedly attenuated both in CU10 and CI10 without significant difference between CU10 and CI10. Accumulation of immune cells did not differ between CU10 and CI10. The results indicate that drinking citrus fruit juice attenuates vascular remodeling partly via a reduction of oxidative stress $^{(151)}$.

The cardiovascular effects of Citrus aurantifolia fruit were studied experimentally. The antihypertensive effect was tested on three experimental hypertensive models including cadmium induced hypertensive model, glucose induced hypertensive model, Egg feed diet induced hypertensive model, and normotensive model. The systolic pressure, diastolic pressure, mean blood pressure and heart rate of Spargue Daweley rats were measured by tail cuff method from the tail of rats using non-invasive blood pressure instrument and body weights were also measured. Three different doses were used for screening $0.25,05$, and $0.75 \mathrm{~g} / \mathrm{kg}$, orally given and there effects on normotensive rats were observed at $2 \mathrm{hr}, 4 \mathrm{hr}$ and $6 \mathrm{hr}$ intervals. The dose of $0.75 \mathrm{~g} / \mathrm{kg}$ was selected because it significantly reduced the mean blood pressure, systolic blood pressure, diastolic blood pressure, and heart rate. The methanol extract of Citrus aurantifolia, administered at the dose of $0.75 \mathrm{mg}$ orally, significantly $(\mathrm{p}<0.01)$ reduced systolic blood pressure, mean blood pressure, diastolic blood pressure, heart rate and body weight of Spargue Dawely rats in both normotensive and hypertensive experimental models when compared to control groups ${ }^{(152)}$.

The effects of an aqueous extract of Citrus aurantifolia on arterial blood pressure and on isolated heart and aorta activities was evaluated experimentally. Rabbits were used for the study on the arterial blood pressure using a Ludwig manometer. Albino Wistar rats were used for the isolated heart and aorta activities using isolated organ bath systems. Aqueous extract of Citrus aurantifolia $(4 \mathrm{mg} / \mathrm{kg}-16 \mathrm{mg} / \mathrm{kg}$ bw) produced a dosedependent and significant decrease in rabbit blood pressure $(\mathrm{p}<0.05)$. This hypotension was not prevented by atropine $(2 \mathrm{mg} / \mathrm{kg}$ bw, p>0.05). Aqueous extract $(4 \mathrm{mg} / \mathrm{kg}-16 \mathrm{mg} / \mathrm{kg}$ bw) was dose-dependently reduced hypertension evoked by adrenalin $(30 \mu \mathrm{g} / \mathrm{kg}$ bw). The extract also induced both negative inotropic and chronotropic effects on the heart contractile activity. The extract induced a dose dependent relaxation of contractions produced by adrenalin or by $\mathrm{KCl}$. Aqueous extract of Citrus aurantifolia evoked vasorelaxant effects were totally abolished by removal of the endothelium layer or by a pretreatment with L-NAME ${ }^{(153)}$.

In vitro / in vivo study was designed to determine the effect of Citrus limon on blood parameters, coagulation and anticoagulation factors. In vitro tests revealed highly significant increase in thrombin time and activated partial thromboplastin time by Citrus limon, whereas fibrinogen concentration was significantly reduced in comparison to control, however prothrombin time was not affected significantly. In vivo testing of Citrus limon was carried out at three different doses $(0.2,0.4$ and $0.6 \mathrm{ml} / \mathrm{kg})$ in healthy rabbits. Significant changes were observed in hematological parameters such as erythrocytes, hemoglobin and mean corpuscular hemoglobin concentration. Bleeding time and thrombin time were significantly prolonged and there was increase in protein $\mathrm{C}$ and thrombin antithrombin complex levels. These results may be due to inactivation of thrombin because it significantly decreased fibrinogen concentration and inhibited platelet aggregation. Citrus limon showed maximal anticoagulant effect at $0.4 \mathrm{ml} / \mathrm{kg}$, which suggest that Citrus limon possessed an anti-thrombin component and could prevent thrombosis and playing a cardioprotective role ${ }^{(154)}$.

The protective effect of the ethanolic extract of Otroj, Citrus medica (EEOT) against isoproterenol (ISO)-induced cardiotoxicity was evaluated in rats. Rats were administered EETO (250 and $500 \mathrm{mg} / \mathrm{kg}$ ) or 
vehicle orally for 15 days along with ISO $(85 \mathrm{mg} / \mathrm{kg}, \mathrm{sc})$ on the $14^{\text {th }}$ and $15^{\text {th }}$ day. ISO induced cardiac dysfunction, increased lipid peroxidation and alteration of myocyte-injury specific marker enzymes. ISO also showed an increase in levels of plasma cholesterol, triglycerides (TG), LDL-C, and VLDL-C. Moreover, the histological investigations showed myocardial necrosis and inflammation. EETO treatment brought the above parameters towards normal level. Moreover, in vitro DPPH radical scavenging and $\beta$-carotene-linoleic acid tests of the EEOT exhibited a notable antioxidant activity in both assays used. In addition, histopathological examination reconfirmed the protective effects of EEOT. Accordingly $C$. medica alleviates myocardial damage in ISO-induced cardiac injury and demonstrates cardioprotective potential ${ }^{(155)}$.

The antihypertensive effect of $C$. medica limetta leaves was investigated against the acute response of blood pressure to angiotensin II administration The results showed that different concentrations of the aqueous extract prevented the raise of systolic blood pressure ( $\mathrm{p} \leq 0.001$ vs. vehicle), diastolic blood pressure $(\mathrm{p} \leq 0.0002$ vs. vehicle) and mean blood pressure ( $\mathrm{p} \leq 0.0000$ vs. vehicle); with a dose dependent effect for diastolic pressures at $125-500 \mathrm{mg} / \mathrm{kg}$ dosages. The 500 and $1000 \mathrm{mg} / \mathrm{kg}$ doses inhibited the action of Ang II in similar extent to telmisartan. Toxic signs or deaths were not observed in mice treated with a dose of $2000 \mathrm{mg} / \mathrm{kg}^{(156)}$.

Four-week consumption of orange juice in healthy middle-aged, normal-weight men reduced diastolic blood pressure $(\mathrm{DBP})^{(157)}$. However, the effects of four-week intake of natural and commercial orange (Citrus sinensis) juice (CSJ) on blood pressure was evaluated in healthy volunteers. 22 healthy subjects were included and randomly divided into two groups. Group A consumed commercial CSJ during the first four-week period. After a two-week washout period, they consumed natural CSJ for another four weeks. The procedure was reversed in group B. The participants were asked to drink $500 \mathrm{ml} /$ day of either natural or commercial CSJ twice a day with breakfast and dinner. After drinking commercial CSJ, diastolic and systolic blood pressure were significantly decreased $(5.13 \% ; \mathrm{P}=0.03$ and $-5.91 \% ; \mathrm{P}=0.003$, respectively). However, consumption of natural CSJ did not have significant effects on either diastolic or systolic blood pressure. Higher flavonoid, pectin, and essential oils content of concentrated products compared to natural juice might have been responsible for this effect ${ }^{(158)}$.

An attempt was made to isolate hypotensive substances from a hot water extract of Citrus unshiu. Six flavonoid glycosides were isolated by repeated chromatography and gel filtration after extraction with butanol and treatment with lead subacetate. Each component was intravenously injected into SHR-SP rats $(1 \mathrm{mg} / 100 \mathrm{~g}$ body weight), 3,6-di-C-glucosylapigenin and rutin were found to lower their blood pressure ${ }^{(159)}$.

\section{Hypolipidemic effect:}

The effect of Citrus aurantifolia peel essential oil was studied on serum triglyceride and cholesterols in Wistar rats. Thirty Wistar rats were divided into 5 groups: control, sham, and 3 experimental groups. The animals were treated in 2 phases: first, except for control group, which received normal saline, the rest of the groups were fed with a high cholesterol regimen to induce hyperlipidemia; then, the 3 experimental groups were treated with Citrus aurantifolia peel essential oil in 3 different doses: 25, 50, and $100 \mu \mathrm{l} / \mathrm{kg}$. The sham group demonstrated a significant rise in mean serum triglyceride, cholesterol, and LDL level in comparison with the control group ( $\mathrm{p}<0.05)$. The results of experimental groups treated with peel essential oil in 50 and $100 \mu 1 / \mathrm{kg}$ doses demonstrated a significant reduction in triglyceride, cholesterol, and LDL $(\mathrm{p}<0.01)^{(160)}$.

The effect of Citrus aurantifolia on hepatic lipidomics was studied in female albino rats, it was found that the fresh juice of lime had different effects on cholesterol, riacylglycerol and phospholipid concentrations of the liver. The low concentration of lime juice $(30 \mu \mathrm{l})$ did not showed considerable effect on cholesterol concentration of the liver. Increase in cholesterol concentration was observed only after applying a concentration of $60 \mu \mathrm{l}$. Beyond this concentration, cholesterol concentration was decreased. Therefore, it was demonstrated that peak stimulation for lime juice is $60 \mu \mathrm{l}$. Similar effect also occur for triacylglycerol concentration. However, it caused dose-dependent increase in phospholipids concentration ${ }^{(161)}$.

Eriocitrin (eriodictyol 7-rutinoside), a powerful antioxidative flavonoid in lemon with lipid-lowering effects was evaluated in a rat model of high-fat diet to investigate its mechanism of action. A feeding experiments was conducted in zebrafish with diet-induced obesity. Oral administration of eriocitrin (32 $\mathrm{mg} / \mathrm{kg} /$ day for 28 days) improved dyslipidaemia and decreased lipid droplets in the liver. DNA microarray analysis revealed that eriocitrin increased mRNA of mitochondrial biogenesis genes, such as mitochondria transcription factor, nuclear respiratory factor 1, cytochrome c oxidase subunit 4, and ATP synthase. In HepG2 cells, eriocitrin also induced the corresponding orthologues, and reduced lipid accumulation under conditions of lipid loading. Eriocitrin increased mitochondrial size and mtDNA content, which resulted in ATP production in HepG2 cells and zebrafish ${ }^{(162)}$.

Citrus medica cv Diamante peel extract lowered plasma cholesterol and triglycerides in mice ${ }^{(163)}$.

\section{Anticancer effect:}

Epidemiological studies have shown that the consumption of fruits is associated with a decreased risk of cancer. The ingestion of citrus fruit has been reported to be beneficial for the reduction of certain types of human cancer ${ }^{(164)}$. The in vitro effects of concentrated lime juice (CLJ) extract was evaluated on the 
spontaneous proliferation of human breast carcinoma cell line (MDA-MB-453) and a human lymphoblastoid B cell line (RPMI-8866). CLJ extract was prepared by freeze-drying fresh fruit juice and dialyzing the concentrated extract against phosphate buffered saline in orderto deplete low molecular weight micronutrients such as flavonoids as well as adjusting the $\mathrm{pH}$ of the extract to the physiological range. The effects of different concentrations of the CLJ extract on the spontaneous proliferative responses of the cell lines were determined by $3 \mathrm{H}$-thymidine incorporation after $24 \mathrm{hrs}$ of incubation. CLJ extract had no significant effect on MDA-MB453 cell line, however, using the concentrations of 125,250 , and $500 \mu \mathrm{g} / \mathrm{ml}$ of CLJ extract a significant inhibition of the spontaneous proliferation of RPMI-8866 cell line was detected $(\mathrm{P}<0.05)^{(165)}$.

The bioactive compounds isolated from of seeds of Citrus aurantifolia were found to posses the potential of inhibiting human pancreatic cancer cells. While, the compounds purified from peel had the potential of suppressing the colon cancer cells. The purified compounds from seeds exhibited significant inhibition of Panc-28 cells with $\mathrm{IC}_{50}$ values in the range of 18.1-100 $\mu \mathrm{M}$, which was confirmed by viable cell count. DNA fragmentation and expression of proteins in cells treated with compounds showed the induction of apoptosis through p53 and caspase-3 mediated pathway. The volatile oil showed 78 per cent inhibition of human colon cancer cells (SW-480) with $100 \mu \mathrm{g} / \mathrm{ml}$ concentration at $48 \mathrm{~h}$. Lime volatile oil showed DNA fragmentation and induction of caspase-3 up to 1.8 and two folds after 24 and $48 \mathrm{~h}$, respectively ${ }^{(71)}$.

Citrus aurantifolia fruit volatile oil showed 78\% inhibition of human colon cancer cells (SW-480) with 100 $\mu \mathrm{g} / \mathrm{ml}$ concentration at $48 \mathrm{~h}$. Lime volatile oil showed DNA fragmentation and induction of caspase-3 up to 1.8 and 2 - folds after $24 \mathrm{~h}$ and $48 \mathrm{~h}$, respectively. Analysis of apoptosis-related protein expression further confirmed apoptosis induction by lime volatile oil ${ }^{(166)}$

The genotoxic effect of the crude volatile oils $(0.005,0.010,0.025,0.050,0.075,0.1 \mathrm{ppm})$ of Citrus limon fruit peels was investigated through estimation of mitotic index (MI) and blast index (BI) in human lymphocytes after treatment with prepared concentrations. The results showed that volatile oils from maturated and non maturated lemon peels possessed genetic effect by increasing MI and BI value of treated lymphocytes. It also appeared that volatile oils stimulated increasing the production of lymphocytes but with more than synergistic treatment with (PHA). Otherwise, It was also found that volatile oils exerted toxic effects against lymphocytes viability ${ }^{(167)}$.

The antimutagenicity and anticancer effect of Citrus medica fruit juice were evaluated on human astrocytoma cancer cells cultured in DMEM (Gibco), cancer cell line were treated by half-ripe and ripe Citrus medica fruit juice and cellular vital capacity was determined by MTT. The Citrus medica fruit juice was subsequenthy evaluated in terms of antimutagenicity and anticancer properties by a standard reverse mutation assay (Ames Test) which was performed with histidine auxotroph strain of Salmonella typhimurium (TA100). By MTT, human astrocytoma cell line revealed a meaningful cell death when compared with controls $(\mathrm{P}<0.01)$. In Ames Test, the fruit juice prevented the reverted mutations and the hindrance percent of half-ripe Citrus medica was $71.7 \%$ and ripe Citrus Medica was $34.4 \%$ in antimutagenicity test and this value in anticancer test was $83.3 \%$ and $50 \%$ in half-ripe Citrus medica and ripe Citrus medica respectively ${ }^{(168-169)}$.

C. limetta root extract at the concentration of $500 \mu \mathrm{g} / \mathrm{ml}$ was found to be lethal towards the larvae of brine shrimp (Artemia franciscana) in a study conducted in the Amazonas state of Brazil, which can serves as a prescreen to existing cytotoxicity and antitumor assays ${ }^{(170)}$.

The antitumor activity of methanol extract of peel of Citrus limetta fruits (MECL) was evaluated against Ehrlich ascites carcinoma (EAC) cell line in Swiss albino mice. Twenty-four hours after intraperitoneal inoculation of tumor EAC cells in mice, MECL was administered at 200 and $400 \mathrm{mg} / \mathrm{kg}$ bw, ip daily for nine consecutive days. On the $10^{\text {th }}$ day, half of the mice were sacrificed for the estimation of tumor growth (tumor volume, viable and non-viable tumor cell counts), and hematologic parameters (red blood cells, white blood cells and hemoglobin). The rest animals were kept alive for assessment of survival parameters (median survival time and percentage increase in life span of EAC bearing mice). Intraperitoneal administration of MECL at the doses of 200 and $400 \mathrm{mg} / \mathrm{kg}$ for nine days to the carcinoma induced mice demonstrated a significant $(\mathrm{P}<0.001)$ decrease in tumor volume, viable tumor cell count, tumor weight and a significant $(\mathrm{P}<0.001)$ improvement in hematologica parameters and life span as compared to the EAC control mice. The results establishes marked and dose dependant antitumor effect of Citrus limetta fruit peel against Ehrlich ascites carcinoma bearing Swiss mice $^{(171)}$.

Limonene, one of the main constituents of citrus species fruit, reduces the risk of mouth, skin, lung, breast, stomach and colon cancer. Hesperidin, and its flavone analogue, diosmin, also exerted anti-carcinogenic activities in various in vivo studies. The polymethoxylated flavones have shown strong anti-proliferative action against cancer cells and antigen activated T-lymphocytes. Beta-cryptoxanthin (an orange-red carotenoid) inhibited development of lung cancer ${ }^{(172-173)}$.

A study of the inhibitory effects of two limonoid aglycones (limonin and nomilin) on the formation of benzo[a]pyrene induced neoplasia in the fore stomach of ICR/Ha mice showed that incidence of tumors was reduced by more than $50 \%$ at $10 \mathrm{mg} / \mathrm{dose}^{(174)}$ 
The cytotoxicity of hesperidin from the peel of Citrus sinensis was evaluated gainst different human carcinoma cell lines (larynx, cervix, breast and liver carcinoma cell lines). The results revealed that hesperidin exhibited pronounced anticancer activity against the selected cell lines. $\mathrm{IC}_{50}$ were $1.67,3.33,4.17,4.58 \mu \mathrm{g} / \mathrm{ml}$, respectively $^{(147)}$.

\section{Central nervous effects:}

Preliminary behavioral screening performed with the lemon fruit demonstrates that it promoted sleep in dementia increasing motivational behaviour and improving disturbed behavior ${ }^{(175-176)}$.

The central nervous system (CNS) depressant and anticonvulsant activities of Citrus limon essential oil (EO) were investigated in animal models. The EO $(50,100$ and $150 \mathrm{mg} / \mathrm{kg}$ ) administered by oral route in mice caused a significant decrease in the motor activity of animals when compared with the control group, up to thirty days after the administration and the dose of $150 \mathrm{mg} / \mathrm{kg}$ significantly reduced the remaining time of the animals on the Rota-rod apparatus. Additionally, $C$. limon essential oil was also capable to promote an increase of latency for development of convulsions induced by pentylenetetrazole. The administration of flumazenil, (10 $\mathrm{mg} / \mathrm{kg}$, ip), $\mathrm{GABA}_{\mathrm{A}}$-benzodiazepine (GABA-BZD) receptor antagonist, antagonized the effect of C. limon essential oil at higher dose. C. limon essential oil was also capable to promote an increase of latency for development of convulsions induced by picrotoxin at higher dose. In the same way, the anticonvulsant effect of the EO was affected by pretreatment with flumazenil, a selective antagonist of benzodiazepine site of $\mathrm{GABA}_{\mathrm{A}}$ receptor $^{(177)}$.

The effects of apigenin, a bioflavonoid widely found in citrus fruits, on behavioral changes and inflammatory responses induced by chronic unpredictable mild stress (CUMS) was investigated in rats. When GW9662, a selective peroxisome proliferator-activated receptor gamma (PPAR $\gamma$ ) inhibitor, administered 30min before apigenin, apigenin $(20 \mathrm{mg} / \mathrm{kg}$, intragastrically) for three weeks remarkably ameliorated CUMS-induced behavioral abnormalities, such as decreased locomotor activity and reduced sucrose consumption. In response to oxidative stress, the NLRP3 inflammasome was activated and IL-1 $\beta$ secretion increased in the prefrontal cortex (PFC) of CUMS rats. However, apigenin treatment upregulated PPAR $\gamma$ expression and downregulated the expression of NLRP3, which subsequently downregulated the production of IL-1 $\beta$. In addition, GW9662 diminished the inhibitory effects of apigenin on the NLRP3 inflammasome. Accordingly, the results demonstrated that apigenin exhibited antidepressant-like effects in CUMS rats, possibly by inhibiting IL-1 $\beta$ production and NLRP3 inflammasome expression via the up-regulation of PPAR $\gamma$ expression ${ }^{(178)}$.

Anxiolytic and antidepressant effects and acute toxicity of ethanolic extract (EE) of the aerial parts of Citrus limon were studied in mice. Anxiolytic activity was evaluated using open field and elevated plus-maze tests. The antidepressant effect of the extract was studied by forced swimming test in mice. In the open field test, the oral route administration of EE alone showed significant sedative and antidepressant activities in mice ( $\mathrm{p}<$ 0.05). EE did not alter motor coordination. The EE, at three doses tested, showed antidepressant effect and produced decrease in immobility time. The authors concluded that the EE of the aerial parts of $C$. limon have a sedative effect, which may be mediated by benzodiazepine-type receptors, and also an antidepressant effect where noradrenergic and serotoninergic mechanisms will probably play a role ${ }^{(179)}$.

The effect of Citrus limon on memory of mice was studied using Harvard Panlab Passive Avoidance response apparatus controlled through LE2708 Programmer. Passive avoidance was fear-motivated tests used to assess short or long-term memory of small animals, which measures latency to enter into the black compartment. Animals with Citrus limon treatment showed significant increase in latency to enter into the black compartment after 3 and 24 hours than control ${ }^{(180)}$.

The sedative, anxiolytic and antidepressant effects of essential oil (EO) of leaves from Citrus limon were investigated in mice. The effects of EO were demonstrated by open-field, elevated-plus-maze, rota rod, pentobarbital-induced sleeping time, and forced swimming tests in mice. In the open-field test, EO at the doses of 50,100 and $150 \mathrm{mg} / \mathrm{kg}$, after oral administration, significantly decreased the number of crossings, grooming, and rearing. In the elevated-plus-maze (EPM) test, EO increased the time of permanence and the number of entrances in the open arms. On the contrary, the time of permanence and the number of entrances in the closed arms were decreased. In the rota rod test, EO did not alter motor coordination and, thus, was devoid of effects, as related to controls. In the pentobarbital-induced sleeping time test, EO at the same doses significantly increased the animals sleeping time duration. Since EO, at the doses of 50, 100 and $150 \mathrm{mg} / \mathrm{kg}$, did not show a sedative effect in the open field test, these three doses when used in the forced swimming test, they were producing a decrease in the immobility time, similarly to that of imipramine (positive control). However, the antidepressant effects of EO were not altered by the previous administration of paroxetine. In addition, effects of EO in the forced swimming test were totally blocked by reserpine pretreatment ${ }^{(181)}$.

The behavioral effects of Citrus limon juice was studied in rats at three different doses $(0.2,0.4 \mathrm{and} 0.6 \mathrm{ml} / \mathrm{kg})$, considered as low, moderate and high doses. Anxiolytic and antidepressant activities were specifically assessed twice during 15 days using open field test, elevated plus maze and forced swimming test. In open field test 
Citrus limon, revealed increase in distance travelled, number of central entries and number of rearing's at moderate dose, while in the elevated plus maze, number of open arm entries were found to be increased. Whereas in forced swimming test, there was decrease in duration of immobility and increase in duration of climbing $^{(182)}$.

Factors that enhance the intrinsic growth potential of neurons play a major role in the regeneration and repair of adult neurons following an injury. Fibroblast growth factor (FGF-2) is one of the key players in the origin and growth of neuronal and glialcells through autocrine and paracrine signaling. Water extract of Citrus medica var. sarcodactylis, was found to activate the FGF-2 promoter in transgenic luciferase expression models. Citrus medica treatment on Schwann cells (RSC96) transfected with luciferase reporter plasmid under a FGF-2 promoter, was found to induce the FGF-2 promoter and showed enhanced luciferase expression. The FGF-2 expression was accompanied with an increase in the expression of proteins involved in cell migration and cell proliferation in a dose dependent manner ${ }^{(183)}$.

The effects of Citrus sinensis essential oil was evaluated in the elevated plus-maze followed by the light/dark paradigm in rats. The animals were exposed to the orange aroma (100, 200 or $400 \mathrm{microl})$ for $5 \mathrm{~min}$, while in a Plexiglas chamber and were then immediately submitted to the behavioural tests. At all doses, $C$ sinensis oil demonstrated anxiolytic activity in at least one of the tests and, at the highest dose, it presented significant effects in both animal models, as indicated by increased exploration of the open arms of the elevated plus-maze (time: $\mathrm{p}=0.004$; entries: $\mathrm{p}=0.044$ ) and of the lit chamber of the light/dark paradigm (time: $\mathrm{p}=0.030$ ). In order to discard the possibility that this outcome was due to non-specific effects of any odour exposure, the behavioural response to Melaleuca alternifolia essential oil was also evaluated, using the same animal models, but no anxiolytic effects were observed ${ }^{(184)}$.

\section{Antidiabetic effect:}

To study the hypoglycemic effect of hexane extract of Citrus limon peel, diabetes was induced in rats by a single intraperitonial injection of alloxan $(140 \mathrm{mg} / \mathrm{kg} \mathrm{bw})$. Hexane extract $(200 \mathrm{mg} / \mathrm{kg}$ bw) of Citrus limon peel was administered orally, while metformine hydrochloride $(175 \mathrm{mg} / \mathrm{kg} \mathrm{bw})$ was used as a standard drug. The results showed that hexane extract exerted significant hypoglycemic activity and the activity of extract was comparable to that of standard drug ${ }^{(185)}$.

The effect of oral treatment with citrus peel extracts on wound repair of the skin was studied in diabetic rats. The extracts were estimated for vitamin $\mathrm{C}$ and total carotenoid contents prior to animal study. Diabetes mellitus was induced in rats by intraperitoneal injection of a single dose of streptozotocin (STZ, 75 $\mathrm{mg} / \mathrm{kg} \mathrm{bw}$ ). One week after diabetes induction, full thickness excision wounds were made in hyperglycemic rats. The different test groups were treated with different citrus peel extracts orally at the dose of $400 \mathrm{mg} / \mathrm{kg} \mathrm{bw}$ daily for 12 days. The blood glucose, body weight and rate of wound closure of each rat were measured every $3^{\text {rd }}$ day during the experimental period. At the end of experiment, granular tissues of wounds were removed and estimated for hydroxylproline and total protein content. The results showed significant reduction in blood glucose and time to wound closure. Tissue growth and collagen synthesis were significantly higher as determined by total protein and hydroxylproline content ${ }^{(186)}$.

Measurements of the effects of Citrus medica cv Diamante peel extract on the mouse insulinoma MIN6 $\beta$ cells indicated that it exerted direct stimulatory effects on the exocytotic release of insulin in a concentrationdependent manner. Citrus medica cv Diamante peel extract reduced plasma glucose concentration in mice (163)

The antidiabetic and hypolipidemic activity of petroleum ether extract of Citrus medica seeds was studied in streptozotocin (STZ) induced diabetic model in rats. Seed extract was given as (200 and $400 \mathrm{mg} / \mathrm{kg}$, po.) The petroleum ether extract of Citrus medica seeds induced significant reduction ( $\mathrm{p}<0.05)$ of fasting blood glucose, serum cholesterol, serum triglycerides, LDL and VLDL in dose dependent manner after 15 days of drug administration. However, $200 \mathrm{mg} / \mathrm{kg}$ /day seed extract for 15 days was not showing any change in HDL level, while $400 \mathrm{mg} / \mathrm{kg} /$ day dose significantly increased HDL level in diabetic rats ${ }^{(187)}$.

In vivo hypoglycemic, and antidiabetic activity of Citrus medica L. var. Sarcodactylis were confired in Sprague-Dawley-SPF rats and Wistar DIO rats. Insulin secretagogue effect of Citrus medica L. var. Sarcodactylis Hort fruits was confirmed by kinetic analysis on the hypoglycemic patterns of the intraperitoneal glucose tolerance and the insulin-glucose tolerance tests ${ }^{(188)}$.

The antihyperglycemic activity of methanol extract of Citrus limetta fruit peel (MECL) was evaluated in streptozotocin-induced (STZ; $65 \mathrm{mg} / \mathrm{kg} \mathrm{bw}$ ) diabetic rats. Three days after STZ induction, diabetic rats received MECL orally at 200 and $400 \mathrm{mg} / \mathrm{kg}$ bw daily for 15 days. Glibenclamide $(0.5 \mathrm{mg} / \mathrm{kg}$ po) was used as reference drug. Blood glucose levels were measured on $0,4^{\text {th }}, 8^{\text {th }}$, and $15^{\text {th }}$ days of study. Serum biochemical parameters namely, SGOT, SGPT and ALP were also estimated. The TBARS and GSH levels of pancreas, kidney, and liver were determined. MECL significantly $(\mathrm{P}<0.001)$ and dose dependently normalized blood glucose levels and serum biochemical parameters, decreased lipid peroxidation, and recovered GSH as compared to those of STZ control ${ }^{(189)}$. 
The inhibitory effect of the aqueous Citrus limetta peel extract on the metabolism of carbohydrates was studied. The extract inhibited primarily the enzyme $\alpha$-amylase by $49.6 \%$ at a concentration of $20 \mathrm{mg} / \mathrm{ml}$ and to a lesser extent the enzyme $\alpha$-glucosidase with an inhibition of $28.2 \%$ at the same concentration. This inhibition was likely due to the high polyphenol content in the Citrus limetta peel (19.1 mg GAE/g). Antioxidant activity of the Citrus limetta peel demonstrated dose-dependent antioxidant activity , varying from $6.5 \%$ at $1.125 \mathrm{mg} / \mathrm{ml}$ to $42.5 \%$ at $20 \mathrm{mg} / \mathrm{ml}$. The results showed that these polyphenolic compounds having both antihyperglycemic and antioxidant activities ${ }^{(190)}$.

The anti-diabetic potential of orange peel and juice was attributed to anti peroxidation, inhibition of $\alpha$ amylase enzyme activity responsible for the conversion of complex carbohydrates to glucose, increased hepatic glycogen content, stimulation of insulin secretion, and repair of secretory defects of pancreatic $\beta$ cells ${ }^{(191-192)}$.

The effects of four different concentrations of peel extract from Citrus sinensis (CS) were investigated in male mice, the results revealed that they exerted glucose lowering and antiperoxidative activities. In a separate experiment their potential was evaluated with respect to the regulation of alloxan induced diabetes mellitus. While a single dose of alloxan $(120 \mathrm{mg} / \mathrm{kg})$ increased the serum levels of glucose and alpha-amylase activity, rate of water consumption and lipid peroxidation (LPO) in hepatic, cardiac and renal tissues with a parallel decrease in serum insulin level, administration of $25 \mathrm{mg} / \mathrm{kg}$ of CS was found to normalize all the adverse changes induced by alloxan, revealing the antidiabetic and anti peroxidative potential of tested fruit peel extracts $^{(193)}$.

\section{Antiinflammatory and analgesic effects:}

The inhibitory effect of pectin at different degrees of esterification (DEs) on the expressions of inducible nitric oxide synthase (iNOS) and cyclooxygenase-2 (COX-2) in lipopolysaccharide (LPS)-activated macrophages was investigated. Western blot and RT-PCR analyses demonstrated that $30 \%$ esterified pectin (DE30), DE60 pectin, and DE90 pectin significantly inhibited the protein and mRNA expressions of iNOS and COX-2 in LPS-activated macrophages, and DE90 pectin was the most-potent inhibitor. To clarify the mechanisms involved, DE90 pectin was found to inhibit the phosphorylation of MAPKs and IKK kinase activity. In addition, DE90 pectin inhibited the activation of NF-kB and AP-1 by electrophoretic mobility shift assay and transient transfection experiments. DE90 pectin bind with LPS, and might result in decreasing binding of LPS to its receptor ${ }^{(194)}$.

Orally, Citrus limon essential oil (EO) $(50,100$, and $150 \mathrm{mg} / \mathrm{kg})$ significantly reduced the number of writhes, and, at highest doses, reduced the number of paw licks. Naloxone antagonized the antinociceptive action of EO (highest doses), this suggested, at least, the participation of the opioid system ${ }^{(134)}$.

The ethanolic extract of peels of Citrus limon (Burm) fruit was screened for its anti-nociceptive property using both chemical and thermal methods of nociception in rats.

The extract at doses 250 and $500 \mathrm{mg} / \mathrm{kg}$ po, showed nociceptive property in both chemical and thermal methods. The activity exhibited by the extract was comparable to that of the standard drug, diclofenac sodium $(15 \mathrm{mg} / \mathrm{kg})^{(195)}$.

The anti-inflammatory study of the stem and root barks of Citrus medica var. sarcodactylis Swingle has led to the isolation of new anti-inflammatory compounds. The new anti-inflammatory components included xanthyletin, nordentatin, atalantoflavon and lonchocarpol A, which displayed potent nitric oxide (NO)reducing activity in microglial cells ${ }^{(196)}$.

The anti-inflammatory and analgesic activities of ethyl acetate extract of Citrus medica peel (EtCM) $(200,300$ and $400 \mathrm{mg} / \mathrm{kg})$ were studied on carrageenan induced inflammatory pain in rats. Anti-inflammatory activity was assessed by measuring paw volume in rats. Analgesic activity was evaluated for its central and peripheral pharmacological actions by using hot plate, plantar, pin prick and mechanical allodynia tests in rats. EtCM $(400 \mathrm{mg} / \mathrm{kg})$ produced significant analgesic and anti-inflammatory effects ${ }^{(138)}$.

The analgesic effect of fresh decoction of Citrus medica fruits was studied in rats. The decoction was prepared from fresh fruits in distilled water and the volume was reduced to $1 / 4^{\text {th }}$. Three doses of decoction $(1$, 2 and $4 \mathrm{ml} / \mathrm{kg}$ po) were tested for analgesic activity using tail immersion method and hot plate method. Diclofenac sodium $(10 \mathrm{mg} / \mathrm{kg}$ ip) was used as standard. The decoction at doses (2 and $4 \mathrm{ml} / \mathrm{kg})$ showed significant increase in latency to flick compared to control in tail immersion method. Whereas the decoction of Citrus medica at all three doses showed significant increase in the mean basal reaction time in hot plate method. In both methods, analgesic effect of $4 \mathrm{ml} / \mathrm{kg}$ decoction was observed comparable to the standard $\operatorname{drug}^{(197)}$.

Methanol extracts of peel of Citrus limetta fruits (MECL) were evaluated in two dose levels (200 and $400 \mathrm{mg} / \mathrm{kg}$ ) in histamine, carrageenan and dextran induced acute rat paw oedema models for their antiinflammatory potential. MECL was able to significantly $(\mathrm{p}<0.001)$ reduce the inflammatory potential produced by different inflammatory mediators in a dose dependant manner. MECL was able to produce significant antiinflammatory activity better than the reference drug used (phenylbutazone $100 \mathrm{mg} / \mathrm{kg} \mathrm{bw} \mathrm{po)}{ }^{(198)}$. Carotenoids, 
zeaxanthin and beta-cryptoxanthin, were the phytonutrients of Citrus sinensis which reduce remarkably the risk of rheumatoid arthritis. Persons consuming high amount of zeaxanthin and cryptoxanthin showed 52\% less chances of developing rheumatoid arthritis ${ }^{(65)}$.

The effect of orange juice on cellular modifications induced by a fatty meal was investigated. 18 apparently healthy subjects consumed a fatty meal, during which they drunk orange juice, either blond or red, or water, according to a randomized cross-over design. Two hours after the end of the fatty meal, both white blood cell (WBC) and platelet counts significantly increased (12.5 and 5\%, respectively), while mean platelet volume decreased and a $25 \%$ release of myeloperoxidase (MPO) from polymorphonuclear leukocyte occurred. Both juices significantly prevented WBC increase and MPO degranulation, in respect to control. Triglycerides significantly increased (42\%) after the fatty meal, but at a lower extent when red orange juice was consumed with the meal (20\%), in respect to blond orange juice or control. This effect was statistically significant in the subgroup subjects with hypertriglyceridemia. Vascular stiffness (augmentation index), measured by EndoPAT2000, significantly decreased after the meal only in conjunction with red orange juice. Accordingly, in healthy subjects the concomitant intake of orange juice may prevent the low-grade inflammatory reaction induced by a fatty meal, at cellular and possibly at vascular function levels ${ }^{(199)}$.

Ultraviolet light (UV) induced an inflammatory response in the skin by cyclooxygenase (COX)-2 expression and prostaglandin $\mathrm{PGE}_{2}$ production. Orange peel which contained polymethoxyflavonoids (PMFs) as a major ingredient, which have anti-inflammatory activity, has been used as a natural medicine. The extract suppressed UVB-induced COX-2 expression and PGE2 production in HaCaT cells. Furthermore, the extract acted as a peroxisome proliferator-activated receptor (PPAR)- $\gamma$ agonist. The suppression of UVB-induced COX-2 expression by this extract was inhibited by GW 9662 and T0070907, which were both PPAR- $\gamma$ antagonists. It was therefore suggested that orange peel extract, containing high levels of PMFs, suppresses UVB-induced COX-2 expression and PGE 2 production through PPAR- $\gamma^{(200)}$.

\section{Reproductive effects:}

Studies have shown that lime juice destroys sperm cells, fifty percent of Citrus aurantifolia juice wiped out 2000 of sperm cells in 30 seconds. The high acidity of Citrus aurantifolia juice may probably responsible for this destruction ${ }^{(123)}$. The effect of lime juice was studied on the fetal parameters of SpragueDawley rats. The estrous cycles of the female rats were studied for the first 16 days to establish cyclicity. The rats were mated with male SD rats of proven fertility on the estrous day (heat period) of estrous cycle. Rats in group I received $1 \mathrm{ml}$ of undiluted lime juice while rats in group II received distilled water by gastric gavage. The rats were sacrificed on the $20^{\text {th }}$ day of gestation and fetal parameters were evaluated. There was a reduction in the number of fetus of treated pregnant rats when compared to the control. There was a significant reduction in the crown-rump length, weight and umbilical cord length of the fetus when compared with the control. Accordingly, lime juice showed abortificient effect but no obvious teratogenic effect was observed ${ }^{(123)}$.

The anti fertility effect of Citrus limonum seeds was studied on male rats. Male albino rats were orally treated with alcoholic extract and its fractions for 30 and 60 days. Testis and epidadymis were removed and tested for sperm count, sperm motility, sperm morphology in addition to histopathologcal examination. sperm counts were also studied 90 days after discontinuation of the treatment to see reversibility of effect. 60 days treatment significantly decreased the sperm count. Size and weight of testis and epidadymis were reduced indicating atrophic changes in testis and epididymis. It caused drastic effect on sperm motility and morphology which decreased fertility. Sperm counts returned to normal after 90 days ${ }^{(201)}$.

The petroleum ether, alcoholic and aqueous extracts of Citrus limonum seeds were investigated for anti-fertility effect in female albino mice. The extracts were administered orally for 7 days after insemination (i.e. post-ovulatory test). The control group received $4 \%$ gum acacia. The animals were examined for implantation sites on $10^{\text {th }}$ day of pregnancy. The number of pups delivered at term was recorded for each group. The alcoholic extract showed significant anti-fertility effect as compared to petroleum ether and aqueous extracts. The alcoholic extract was subjected for fractionation and the fractions were again tested for their antifertility effect. The fraction of ethyl-acetate showed most encouraging anti-fertility activity. In second part of the study, the alcoholic extract and its ethyl-acetate fraction were subjected to evaluation of their mechanism of action and it was found that their principal mode of action is as an anti-zygotic agent. Withdrawal of the treatment, resulted in complete restoration of fertility ${ }^{(202)}$.

Estrogenic /anti-estrogenic activities of alcoholic extract of Citrus limonum seeds was studied in Albino rats. The standard drug estrogen was given sub-cutaneiously and test drug, alcholic extract of lemon seeds was given orally for 7 days from $8^{\text {th }}$ to $14^{\text {th }}$ days of ovariectimised rats. The extract treated rats exhibited estrogenic effect, which include vaginal epithelium cell cornification and increased in uterine weight. For further supporting the estrogenic activity of the extract, isolated rats uterus preparation was mounted, and it showed that alcoholic extract of lemon seeds produced the contraction as pretreatment with stelbistrol ${ }^{(203)}$.

Three extracts of the peels of Citrus medica including oil, ethanolic and chloroform extract were investigated for antifertility activity. The alcoholic extract at the dose of $2.5 \mathrm{gm} / \mathrm{kg}$ and the chloroform extract at 
dose of $1.0 \mathrm{gm} / \mathrm{kg}$ on female wistar rats on days 1-7 post-coital, exhibited significant anti-implantation activity. While, the oil extract at the dose of $100 \mathrm{mg} / \mathrm{kg}$ on days $1-7$ didn't exhibit significant anti-implantation activity ${ }^{(204}$ Petroleum ether extract of Citrus medica seeds, was administered orally (400 $\mathrm{mg} / \mathrm{kg}$ body weight) for 30 days to study its effect on fertility in Wistar strain Albino rats. Animal were divided into 3 groups: Group I, received 400mg petroleum ether extract $/ \mathrm{kg}$ in $0.2 \mathrm{ml}$ Tween-80 (1\%) orally for 30 days. Group-II, received only $0.2 \mathrm{ml}$ Tween-80 (1\%)/kg for 30 days and left untreated for another 30 days to served as control. GroupIII: received $400 \mathrm{mg}$ petroleum ether extract $/ \mathrm{kg}$ in $0.2 \mathrm{ml}$ Tween-80 $(1 \%)$ for 30 days and left untreated for next 30 days to see the withdrawal effects. The results were analysed depending on gravimetric, histological, histometric and biochemical parameters. Histologically, ovary and uterus in extract treated rats showed reduced number of healthy follicles, regressing follicles and also elevation in corpora lutea in the Group I and II. For the study of withdrawal effects of this extract in Group III, the results indicated that the animals returned to normal and regained gonadotrophin secretion similar to that of control rats ${ }^{(205)}$.

Petroleum ether, benzene and ethanol extracts of the seeds of Citrus medica were administered orally at the dose level of 200 and $400 \mathrm{mg} / \mathrm{kg}$ to adult female albino rats for 30 days. The estrous cycle of these rats was irregular with prolonged proestrus and estrous, reduced metestrus and diestrus phase during the experimental period. At autopsy on day $31^{\text {st }}$, petroleum ether extract treated rats showed reduced ovarian weight, benzene extract treated rats showed increased ovarian weight and ethanol extract treated rats showed non-significant change in the weight of ovary. Histological changes of the ovary indicated increases in the number of atretic follicles but decreases in the number of healthy developing follicles, Graafian follicles and corpora lutea. The total cholesterol, activity of acid and alkaline phosphatase and ascorbic acid content of the ovary were increased, whereas, protein and glycogen content were decreased. The uterine weight and its micrometric measurements in the treated rats were increased significantly. However, petroleum ether extract of Citrus medica seeds was more effective in causing these changes comparing to other extracts ${ }^{\text {(206) }}$.

Estrogenic/anti-oestrogenic activities of petroleum ether extract of Citrus medica seeds were studied in albino rats. The extract at the dose level of 200 and $400 \mathrm{mg} / \mathrm{kg}$ body weight was administered for seven days to immature ovariectomised rats, along with or without $1 \mu \mathrm{g}$ ethinyl estradiol. The extract-treated rats exhibited estrogenic effects, which included increase in uterine weight and vaginal epithelial cell cornification. The micrometric measurements of the uterus and its components were increased and glands showed high secretory activity. When the extract was tested in 30-day-old immature rats, they exhibited opening of vagina on the fifth day and cornification of vaginal epithelial cells, which was about 10 days earlier compared to controls, which further supporting the estrogenic activity of the extract. Hence, these results strongly indicate the potent estrogenic nature of petroleum ether extract of Citrus medica seeds ${ }^{(207)}$.

The estrogenic activity of petroleum ether extract of Citrus medica leaves was studied in immature female rats. The petroleum ether extract proved to retain high estrogenic activity in immature female rats. Oral administration of petroleum ether extract of Citrus medica in ovariectomized immature female Wistar rats for 7 days in a dose of $400 \mathrm{mg} / \mathrm{kg}$ resulted in significant increase in the uterine weight $(\mathrm{g})(1.7 \pm 0.11)$ when compared with ovariectomized control rats $(1.3 \pm 0.07)^{(208)}$.

\section{Gastrointestinal effect:}

The antiulcer activity of aqueous extract of the fruits of Citrus medica was evaluated against ethanolinduced ulcers in rats. The rats were pretreated with the extract at two doses ( 250 and $500 \mathrm{mg} / \mathrm{kg}$ po $)$ and the antiulcer effect was compared with that of ranitidine $(20 \mathrm{mg} / \mathrm{kg}$ po $)$. The extract of both doses showed a significant reduction in ulcer formation. Histopathological sections showed significant decrease in mucosal ulceration, inflammatory mucosal changes and submucosal edema compared to ethanol treated group and the ranitidine group. It was concluded that, the fruits of Citrus medica possesses significant antiulcer activity against ethanol-induced ulcers in rats and the antiulcer activity could be due to the presence of flavonoids as these compounds have well documented antiulcer activity ${ }^{(209)}$.

\section{Respiratory effect:}

A study among British children found a positive association between fresh fruit consumption and the level of forced expiratory volume in one second (FEV1). The association was more pronounced in wheezers than non-wheezers ${ }^{(210)}$

An Italian study, followed over 18,000 children aged 6-7 years and found that those eating the most citrus fruit (oranges, tangerines, and grapefruit), along with kiwifruit, had a reduced risk of wheezing. The protective effect of citrus did not appear to be dose related. The authors attributed the lung health benefiting properties of citrus and kiwifruit to their high concentration of vitamin $\mathrm{C}^{(211)}$.

\section{Dental effect:}

The effects of Citrus aurantifolia (CA) extract was studied on smear layer removal in different parts of root canals. Thirty-nine single-rooted human teeth were randomly divided into three experimental and one 
control groups. Teeth were instrumented using MTwo rotary instruments. Root canals were irrigated with $\mathrm{NaOCl}$ during instrumentation. The canals in each group were irrigated with one of the following: completed mixture of Citrus aurantifolia extracts, 17\% EDTA, and alcoholic extract of CA. Distilled water was used for the control group. The irrigants were left within the canal for 20 minutes, and then rinsed with normal saline solution. Teeth were subsequently split longitudinally into 2 halves, and the canals were examined by a scanning electron-microscope. Cleanliness was evaluated using a five point scoring system. Statistical significant difference was found between groups $(\mathrm{P}<0.05)$. The smear layer was more effectively removed with $17 \%$ EDTA compared to alcoholic CA extract. However, they were both able to remove the smear layer in the coronal segment. Completed CA extract removed more smear layer in coronal and middle parts compared with the alcoholic extract $(\mathrm{P}=0.001)$; however, there was no significant difference in the apical part ${ }^{(212)}$.

\section{Antiallergic and immunological effect:}

Gencydo®, a combination of Citrus limon juice and aqueous quince (Cydonia oblonga) extract has been used traditionally in anthroposophical medicine for treating patients with allergic rhinitis or asthma. The anti-allergic effects of this preparation was investigated in vitro by using cell lines and primary cells in various biological and immunological endpoints. The release of soluble mediators from basophilic cells, mast cells and lung epithelial cells, which were essential for the initiation of early- and late-phase allergic reactions, was analyzed in relation to the synthetic anti-allergic drugs azelastine and dexamethasone. In addition, the impact of Gencydo ${ }^{\circledR}$ on the viability and activation of GM-CSF-activated eosinophil granulocytes was investigated. Gencydo ${ }^{\circledR}$ reduced the degranulation and histamine release of IgE-activated basophilic cells and mast cells and inhibited the IgE- and PMA/A23187-induced increases in IL-8, TNF- $\alpha$ and GM-CSF production in mast cells. The effects were comparable to that of azelastine and dexamethasone. Furthermore, Gencydo® partially blocked eotaxin release from human bronchial epithelial cells, but has no impact on the viability and activation of GM-CSF-activated eosinophil granulocytes. The results gave a rational base for the topical use of Gencydoß in treatment of allergic disorders through the down regulation of soluble mediators, which were essential for the initiation and maintenance of allergic reactions ${ }^{(213)}$.

The effects of the combined Citrus medica ssp. limonum /Cydonia oblonga $(0.01 \mathrm{~g} / \mathrm{ml}$ of each one), separate products of Citrus medica ssp. limonum $(0.01 \mathrm{~g} / \mathrm{ml})$ and Cydonia oblonga $(0.01 \mathrm{~g} / \mathrm{ml})$ were investigated on the immunological pathways involved in seasonal allergic rhinitis (SAR). Peripheral blood mononuclear cells (PBMCs) from five healthy and five grass pollen allergic donors were isolated and analyzed in vitro after polyclonal and allergen-specific stimulation of $\mathrm{T}$ cells in the presence of the three extracts. The analyses demonstrated acceptable cell survival with no signs of toxicity. Citrus mainly had a selective effect on reducing allergen-specific chronic inflammatory (TNF- $\alpha$; Citrus compared to Cydonia and Citrus/Cydonia: -87.4 (P< 0.001) and $-68.0(\mathrm{P}<0.05)$, resp.) and Th2 pathway activity (IL-5; Citrus compared to Cydonia: -217.8 $(\mathrm{P}<0.01)$; while, both Cydonia and Citrus/Cydonia mainly affected the induction of the allergen-specific Th1 pathway (IFN- $\gamma$; Cydonia and Citrus/Cydonia compared to Citrus: $3.8(\mathrm{P}<0.01)$ and $3.0(\mathrm{P}<0.01)$, respectively). Citrus and Cydonia demonstrated different working mechanisms in the treatment of SAR and the combination product did not demonstrate larger effects than the separate preparations ${ }^{(214)}$.

The immunomodulatory and antiallergic properties of preparations from lemon, Citrus medica L. (citrus), and Cydonia oblonga, which were used in pharmaceutical products to treat patients suffering from allergic disorders, were investigated. Preparations were analyzed with respect to their impact on the degranulation capacity from basophilic cells as well as mediator release from activated human mast cells in vitro, including IL-8 and TNF- $\alpha$ secretion. The results showed that the degranulation of basophilic cells was diminished only in the presence of Citrus. Furthermore, Citrus and Cydonia both inhibited the production of IL- 8 and TNF- $\alpha$ from human mast cells, and at low concentrations additive effects were observed ${ }^{(215)}$.

To compare the efficacy and safety of two routes of administration (nasal spray versus subcutaneous injections) of Citrus/Cydonia in seasonal allergic rhinitis, a randomised, comparative clinical trial with two parallel groups was carried out. After a one- or two-week wash-out period, 23 patients were randomized, to a 6week treatment period and the immunological and symptom severity changes and safety were evaluated. Both routes of administration were safe, they demonstrate therapeutic immunological and clinical effects ${ }^{(216)}$.

\section{Effect on body weight:}

The effects of Citrus aurantifolia essential oils in reducing body weight, individually and in coadministration with ketotifen, an antihistaminic drug that causes weight-gain, has been investigated using mice model. During the 45 days experimental period, the mice that received ketotifen demonstrated an enhancement both in the amount of food intake and body weight compared to the control group. Groups treated with Citrus aurantifolia essential oil displayed reduction in body weight and food consumption, possibly through promoting anorexia which might have played a role in weight loss. Interestingly, co-administration of the Citrus aurantifolia essential oil and ketotifen caused significant suppression in gaining weight, as well as decreased 
body weights of mice. The results suggested that Citrus aurantifolia essential oil played an important role in weight loss and could be useful in treatment of drug-induced obesity and related diseases ${ }^{(217)}$.

\section{Effect on bone loss:}

The efficacy of Citrus aurantifolia $c v$. Swingle and Citrus sinensis $c v$. Liucheng against osteoporosis was evaluated in an ovariectomized rat model. Administration of Citrus extracts increased trabecular bone mineral content and bone mineral density of tibia, improved the levels of phosphorus and calcium. The results demonstrated that Citrus extracts reduced bone loss in ovariectomized rats ${ }^{(218)}$.

\section{Anti-cholinesterase effect:}

The anti-cholinesterase activity of Citrus aurantifolia peel and leaves from different areas of growth, was studied. $n$-Hexane fractions of both peel and leaves showed a good acetylcholinesterase inhibitory activity with $\mathrm{IC}_{50}$ values in the range $91.4-107.4 \mu \mathrm{g} / \mathrm{ml}^{(87)}$.

\section{Xanthine oxidase inhibitory effect:}

Among the many extracts tested, the Citrus limetta peel extract exhibited highest potency of xanthine oxidase inhibition $\left(\mathrm{IC}_{50}=40.16 \pm 0.88 \mu \mathrm{g} / \mathrm{ml}\right)^{(219)}$.

\section{Decreasing the risk of renal stone:}

It was recorded that when women drank 1/2 liter of orange juice daily, their urinary $\mathrm{pH}$ value and citric acid excretion increased thereby diminishing the risk of forming calcium oxalate stones significantly ${ }^{(220)}$.

\section{Feeding value:}

A feeding trial was conducted with thirty six mixed breeds of rabbits to assess the feeding value of sun dried sweet orange (Citrus sinensis) fruit pulp meal (SOPM). The sweet orange peel meal was analyzed for its proximate nutrients and its crude fiber constituents. The experimental rabbits were randomly assigned to six dietary treatments: T0, T5, T10, T15, T20 and T25 in which SOPM replaced maize at 0, 5, 10, 15, 20 and 25\%, respectively. The rabbits were fed these diets for 84 days during which performance and nutrient digestibility were evaluated. Experimental diets had significant effects $(p<0.05)$ on the body weight gain, water intake, water: feed ratio, protein efficiency ratio and final live weight. Coefficient of digestibility and nutrient digestibility, were not adversely affected by the inclusion of SOPM in the diets. The results revealed the possibility that sweet orange fruit pulp meal can be used as a replacement feedstuff for maize in the ration of grower rabbit up to a level of $20 \%^{(221)}$.

\section{Effect on liver metabolism:}

The possible action of the Citrus aurantium extract on liver metabolism was investigated on isolated perfused rat liver. The isolated perfused rat liver was used to measure catabolic and anabolic pathways, including oxygen uptake and perfusion pressure. The Citrus aurantium extract and $p$-synephrine increased glycogenolysis, glycolysis, oxygen uptake and perfusion pressure. These changes were partly sensitive to $\alpha$ and $\beta$ - drenergic antagonists. $p$-Synephrine $(200 \mu \mathrm{M})$ produced an increase in glucose output that was only $15 \%$ smaller than the increment caused by the extract containing $196 \mu \mathrm{M} p$-synephrine. At low concentrations the Citrus aurantium extract tended to increase gluconeogenesis, but at high concentrations it was inhibitory, opposite to what happened with $p$-synephrine. The action of the Citrus aurantium extract on liver metabolism is similar to the well known actions of adrenergic agents and can be partly attributed to its content of $p$ synephrine. Many of these actions were catabolic and compatible with the weight-loss effects usually attributed to Citrus aurantium ${ }^{(22)}$.

\section{Protective effect:}

The cytoprotective effects of Citrus aurantifolia was evaluated against Aflatoxin B1 (AFB1)induced liver injury in rat model. Wistar albino rats were divided into five groups. Group I served as the control. Group II treated with vehicle, dimethyl sulfoxide (DMSO) a single intraperitoneally intraperitoneally on day 5. Group III received AFB1-alone $(1 \mathrm{mg} / \mathrm{Kg}$ body weight) intraperitoneally in DMSO as a single dose on day 5. Group IV and V received Citrus aurantifolia methanolic extract (MeCA) and Citrus aurantifolia aqueous extract (AqCA) $(500 \mathrm{mg} / \mathrm{Kg}$ body weight, per oral) for 5 days and AFB1 (1mg/kg body weight) intraperitoneally in DMSO as a single dose on day 5. At the end of the $8^{\text {th }}$ day, the livers were collected and used to determine the hepatoprotective activity. Genomic DNA fragmentation was observed by agarose gel electrophoretic pattern in the rat livers. The ultra-structure of the liver cells was studied by electron microscopy. Citrus aurantifolia treatment significantly protected nucleic acid. The treatment was significantly inhibited DNA fragmentation. Nucleus structures were well maintained. The results demonstrate that Citrus aurantifolia has a cytoprotective effect against AFB1-induced liver injury ${ }^{(223)}$. 
The ethanol extract of Citrus limon fruits was evaluated for its effects on experimental liver damage induced by carbon tetrachloride. The ethyl acetate soluble fraction of the extract of Citrus limon. fruits was evaluated on HepG2 cell line. The ethanol extract normalized the levels of aspartate aminotransferase, alanine aminotransferase, alkaline phosphatase, and total and direct bilirubin, which were altered due to carbon tetrachloride intoxication in rats. In the liver tissue, treatment significantly raised the levels of antioxidant enzymes superoxide dismutase and catalase. It improved the reduced glutathione (GSH) levels in treated rats in comparison with $\mathrm{CCl}_{4}$-intoxicated rats. In the histopathologic studies, treated animals exhibited restoration of the liver architecture toward normal. Three doses of ethanol extract $(150,300$, and $500 \mathrm{mg} / \mathrm{kg})$ were evaluated. The results obtained were dose dependent, and the effect of the highest dose was almost equal to the standard silymarin. Significant reduction in cell viability was observed in cells exposed to $\mathrm{CCl}_{4}$. A dose-dependent increase in the cell viability was observed when $\mathrm{CCl}_{4}$-exposed $\mathrm{HepG} 2$ cells were treated with different concentrations of ethyl acetate soluble fraction of the ethanol extract. The highest percentage viability of HepG2 cells was observed at a concentration of $100 \mu \mathrm{g} / \mathrm{ml}^{(224)}$.

Ethylene glycol $(0.75 \% \mathrm{v} / \mathrm{v}$ po in drinking water; 28 days) induced urolithiasis was used to study the protective effect of flavanoid rich fraction of Citrus medica (FFCM) at three dose level (320, 380 and 440 $\mu \mathrm{g} / \mathrm{kg}$ - 28 days; po) in male wistar albino rats. Cystone $(750 \mathrm{mg} / \mathrm{kg}$; po) was used as standard drug. After completion of treatment period of 28 days, $24 \mathrm{hr}$ urine sample and blood were collected. Various physical parameters like body weight, diuresis, $\mathrm{pH}$, kidneys weight (wet and dry) were measured. Various stone forming inhibitors (magnesium and citrate) and promoters (oxalate, calcium, phosphate, uric acid and urea) were analysed in urine, serum and kidney homogenate. Renal function test (BUN and creatinine clearance), antioxidant parameters (MDA and catalase) and crystalluria were also evaluated. FFCM at all dose level significantly prevented EG induced changes in calcium, inorganic phosphate, uric acid, oxalate, urea, citrate, magnesium level; creatinine clearance and oxidative stress. FFCM possessed anti-lithiatic activity in experimentally induced urolithiatic model that can be attributed to its diuretic action, decrease in promoters and increase in inhibitors level as well as antioxidant potential ${ }^{(225)}$.

The hepatoprotective activity of orange essential oils was evaluated in carbon tetrachloride-induced hepatotoxicity in rats. Orange essential oils significantly reduced the serum ALT level when compared to $\mathrm{CCl}_{4}$ group, while it did not affect the serum AST level. The histopathological findings did not show any significant difference between the orange essential oils treated and $\mathrm{CCl}_{4}$ groups ${ }^{(26)}$.

\section{Toxicity and side effects: Citrus aurantifolia}

All sources agree that citrus fruits contain d-limonene. Several sources demonstrate that oxided dlimonene is allergenic, whereas information on unoxided d-limonene is conflicting. Several sources mention that Citrus species contains 5-methoxypsoralene that is phototoxic ${ }^{(227)}$.

The acute toxicity of Citrus aurantifolia indicated that doses up till $3 \mathrm{~g}$ is safe ${ }^{(152)}$. Acute and subchronic toxicities of the water extract from the roots of Citrus aurantifolia were studied in both male and female rats. Oral administration of the extract at a single dose of $5,000 \mathrm{mg} / \mathrm{kg}$ body weight did not produce signs of toxicity, behavioral changes, mortality or differences on gross appearance of internal organs. The subchronic toxicity was determined by oral feeding the test substance at the doses of 300,600 and 1,200 $\mathrm{mg} / \mathrm{kg}$ body weight for 90 days. The examinations of signs, animal behavior and health monitoring showed no signs of abnormalities in the test groups as compared to the controls. The test and control groups (on the $90^{\text {th }}$ day) and the satellite group (on the $118^{\text {th }}$ day) were analyzed by measuring their final body and organ weights, taking necropsy, and examining hematological parameters, blood clinical chemistry and histopathology features. The oral administration of $1,200 \mathrm{mg} / \mathrm{kg} /$ day of the extract of Citrus aurantifolia in male and female rats caused a increase in the liver enzymes, which remained within the normal range, but did not produce a significant histopathological change in the internal organs. In conclusion, the extract from the roots of Citrus aurantifolia administered orally did not cause acute or subchronic toxicities to male and female rats ${ }^{(228)}$.

The subchronic toxicity of Citrus aurantium was evaluated in mice. Mice received for 28 consecutive days a commercial Citrus aurantium dried extract (containing 7.5\% p-synephrine) 400, 2000 or $4000 \mathrm{mg} / \mathrm{kg}$ and psynephrine 30 or $300 \mathrm{mg} / \mathrm{kg}$ by oral gavage. There was a reduction in body weight gain of animals treated with both doses of p-synephrine. Organs relative weight, biochemical and hematological parameters were not altered in all treated mice. There was an increase in reduced glutathione (GSH) concentration in groups treated with Citrus aurantium $4000 \mathrm{mg} / \mathrm{kg}$ and p-synephrine 30 and $300 \mathrm{mg} / \mathrm{kg}$. In glutathione peroxidase (GPx), there were an inhibition of the activity in Citrus aurantium 400 and $2000 \mathrm{mg} / \mathrm{kg}$ and p-synephrine 30 and $300 \mathrm{mg} / \mathrm{kg}$ treated animals, respectively, and there was no alteration in malondialdehyde (MDA) levels ${ }^{(229)}$.

\section{Citrus limonum}

Essential oil of Citrus limonum is generally considered safe and devoid of adverse side effects when administered in recommended doses. The potential capacity of causing sensitisation effects is very weak ${ }^{(230)}$. 
Acute toxicity study of n-hexane extract of $C$. limon peel at $2000 \mathrm{mg} / \mathrm{kg}$ body weight in mice for 14 days did not produce any mortality. There was no significant change in the body weight and food consumption of the animals. The animals did not show any signs of toxicity and resembled the normal animals, which indicated the safety of extract of $C$. limon peel in the experimental species ${ }^{(185)}$.

\section{Citrus medica}

The toxicity of Citrus medica leaves essential oil was studied in rats. The effect of chronic ingestion of a diet treated with different concentrations of essential oil of Citrus medica was studied on body weight, diet consumption, haemoglobin, total and differential leucocyte count, blood glucose, protein, cholesterol, urea levels and glutamic oxalacetic transaminase, glutamic pyruvic transaminase and alkaline phosphatase activity in albino rats. It was found that the Citrus medica oil was nontoxic to test animals and did not induce any adverse effects to the blood, liver function, kidney function, protein, carbohydrate and lipid metabolism of the animals $^{(231)}$. The acute toxicity of the ethanol extract of the whole fruit of Citrus medica was evaluated in rats. Female rats received a single high dose of ethanolic extract of Citrus medica ( $2 \mathrm{~g} / \mathrm{kg}$ orally) by gavage. The animals were observed for toxic symptoms continuously for the first $4 \mathrm{~h}$ after dosing. Finally, the number of survivors was noted after $24 \mathrm{~h}$ and these animals were then maintained for a further 13 days with daily observation. No toxicity symptoms (e.g., convulsions, myosis, mydriasis, diarrhea, increasing respiration, urination, and muscle relaxation) were recorded. The LD50 value by oral route could not be determined as no lethality was observed up to $2.0 \mathrm{~g} / \mathrm{kg}$ of the Citrus medica in the animals ${ }^{(155)}$.

\section{Citrus sinensis}

Essential oil of Citrus sinensis is generally considered as safe and devoid of adverse side effects when administered in recommended doses. The potential capacity of causing sensitization and irritation effects is very weak. Human patch tests with orange essential oil eight per cent in petrolatum had no irritant reaction after 48 hours, no sensitization, and no phototoxic effects ${ }^{(232)}$.

\section{Conclusion:}

This review discuss the chemical constituent, pharmacological and therapeutic effects of Citrus fruits as promising nutraceutical because of its safety and effectiveness.

\section{REFERENCES:}

[1] Al-Snafi AE. Medicinal plants with anticancer effects (part 2)- plant based review. Sch Acad J Pharm 2016; 5(5): 175-193.

[2] Al-Snafi AE. Antiparasitic, antiprotozoal, molluscicidal and insecticidal activity of medicinal plants (part 2) - plant based review. Sch Acad J Pharm 2016; 5(6): 194-207.

[3] Al-Snafi AE. Therapeutic properties of medicinal plants: a review of plants with antifungal activity (part 1). Int J of Pharm Rev \& Res 2015; 5(3):321-327.

[4] Al-Snafi AE. Therapeutic properties of medicinal plants: a review of their dermatological effects (part 1). Int J of Pharm Rev \& Res 2015; 5(4):328-337.

[5] Al-Snafi AE. Therapeutic properties of medicinal plants: a review of plants with anticancer activity (part 1). Int J of Pharmacy 2015; 5(3): 104-124.

[6] Al-Snafi AE. Therapeutic properties of medicinal plants: a review of plants with anti-inflammatory, antipyretic and analgesic activity (part 1). Int J of Pharmacy 2015; 5(3): 125-147.

[7] Al-Snafi AE. Cardiovascular effects of Carthamus tinctorius: A mini-review. Asian Journal of Pharmaceutical Research 2015; 5(3): 199-209.

[8] Al-Snafi AE. Therapeutic properties of medicinal plants: a review of their immunological effects (part 1). Asian Journal of Pharmaceutical Research 2015; 5(3): 208-216.

[9] -Al-Snafi AE. Medical importance of Cichorium intybus - A review IOSR Journal of Pharmacy 2016; 6(3): 41-56.

[10] Al-Snafi AE. Pharmacological importance of Clitoria ternatea - A review IOSR Journal of Pharmacy 2016; 6(3): 68-83.

[11] Al-Snafi AE. The medical Importance of Cicer arietinum - A review IOSR Journal of Pharmacy 2016; 6(3): 29-40.

[12] Al-Snafi AE. Therapeutic properties of medicinal plants: a review of their antiviral

[13] activity (part 1). International Journal of Pharmacological Screening Methods 2015; 5(2): 72-79.

[14] Al-Snafi AE. Therapeutic properties of medicinal plants: a review of plants with cardiovascular effects (part 1). Int J of Pharmacology \& Toxicology 2015; 5(3): 163-176.

[15] Al-Snafi AE. Therapeutic properties of medicinal plants: a review of medicinal

[16] plants with central nervous effects (part 1). Int J of Pharmacology \& Toxicology 2015; 5(3): 177-192. 
[17] Al-Snafi AE. The pharmacological Importance of Antirrhinum majus - A review. Asian J of Pharm Sci \& Tech 2015; 5(4): 313-320.

[18] Al-Snafi AE. Chemical constituents and pharmacological effects of Astragalus hamosus and Astragalus tribuloides grown in Iraq. Asian J of Pharm Sci \& Tech 2015; 5(4): 321-328.

[19] Al-Snafi AE. The chemical constituents and pharmacological importance of Celosia cristata - A review. J of Pharm Biology 2015; 5(4): 254-261.

[20] Al-Snafi AE. The pharmacological importance of Centaurea cyanus- A review. Int J of Pharm Rev \& Res 2015; 5(4): 379-384.

[21] Al-Snafi AE. The chemical constituents and pharmacological importance of Chrozophora tinctoria. Int J of Pharm Rev \& Res 2015; 5(4): 391-396.

[22] Al-Snafi AE. Therapeutic properties of medicinal plants: a review of plants affected smooth muscles functions (part 1). Int J of Pharmacy 2015; 5(2): 90-97.

[23] Snafi AE. A review of medicinal plants with broncho-dilatory effect-Part 1. Scholars Academic Journal of Pharmacy, 2015; 5(7): 297-304.

[24] Al-Snafi AE. Chemical constituents and pharmacological importance of Agropyron repens - A review. Research Journal of Pharmacology and Toxicology 2015; 1 (2): 37-41.

[25] Al-Snafi AE. Clinically tested medicinal plant: A review (Part 1). SMU Medical Journal 2016; 3(1): 99128.

[26] Al-Snafi AE. Chemical constituents and pharmacological effects of Clerodendrum inerme- A review. SMU Medical Journal 2016; 3(1): 129-153.

[27] Al-Snafi AE. Chemical constituents and pharmacological effects of Citrullus colocynthis - A review. IOSR Journal of Pharmacy 2016; 6(3): 57-67.

[28] Al-Snafi AE. Medical importance of Anthemis nobilis ( Chamaemelum nobilis)- A review. Asian Journal of Pharmaceutical Science \& Technology 2016; 6(2): 89-95.

[29] Al-Snafi AE. Adonis aestivalis: pharmacological and toxicological activities- A revew. Asian Journal of Pharmaceutical Science \& Technology 2016; 6(2): 96-102.

[30] Al-Snafi AE. The pharmacological activities of Cuminum cyminum - A review. IOSR Journal of Pharmacy 2016; 6(6): 46-65.

[31] Al-Snafi AE. Medical importance of Cupressus sempervirens- A review. IOSR Journal of Pharmacy 2016; 6(6): 66-76.

[32] Al-Snafi AE. The contents and pharmacology of Crotalaria juncea- A review. IOSR Journal of Pharmacy 2016; 6(6): 77-86.

[33] 1-Al-Snafi AE. The medical importance of Cydonia oblonga- A review. IOSR Journal of Pharmacy 2016; 6(6): 87-99.

[34] Al-Snafi AE. The pharmacology of Crocus sativus- A review. IOSR Journal of Pharmacy 2016; 6(6): 838.

[35] Al-Snafi AE. The chemical constituents and therapeutic importance of Cressa cretica- A review . IOSR Journal of Pharmacy 2016; 6(6): 39-46.

[36] Al-Snafi AE. The Pharmacological and therapeutic importance of Cordia myxa- A review. IOSR Journal of Pharmacy 2016; 6(6): 47-57.

[37] Al-Snafi AE. The contents and pharmacological importance of Corchorus capsularis- A review. IOSR Journal of Pharmacy 2016; 6(6): 58-63.

[38] Al-Snafi AE. The chemical constituents and pharmacological effects of Convolvulus arvensis and Convolvulus scammonia- A review. IOSR Journal of Pharmacy 2016; 6(6): 64-75.

[39] Al-Snafi AE. Medicinal plants possessed anti-inflammatory antipyretic and analgesic activities (part 2)plant based review. Sch Acad J Pharm 2016; 5(5): 142-158.

[40] Al-Snafi AE. Medicinal plants affected reproductive systems (part 2) - plant based review. Sch Acad J Pharm 2016; 5(5): 159-174.

[41] Al-Snafi AE. Chemical constituents and pharmacological effects of Cynodon dactylon- A review. IOSR Journal of Pharmacy 2016; 6(7): 17-31.

[42] Al-Snafi AE. A review on Cyperus rotundus A potential medicinal plant. IOSR Journal Of Pharmacy 2016; 6(7): 32-48.

[43] Al-Snafi AE. Medicinal plants with antidiabetic effects (part 2): plant based review. IOSR Journal of Pharmacy 2016; 6(7): 49-61.

[44] Al-Snafi AE. Medicinal plants with antioxidant and free radical scavenging effects (part 2): plant based review. IOSR Journal Of Pharmacy 2016; 6(7): 62-82.

[45] Al-Snafi AE. Medicinal plants with antimicrobial activities (part 2): Plant based review. Sch Acad J Pharm 2016; 5(6): 208-239.

[46] Al-Snafi AE. A review on chemical constituents and pharmacological activities of Coriandrum sativum. IOSR Journal of Pharmacy 2016; 6(7): 17-42. 
[47] Al-Snafi AE. Medicinal plants with cardiovascular effects (part 2): plant based review. IOSR Journal of Pharmacy 2016; 6(7): 43-62.

[48] Al-Snafi AE. Detoxification capacity and protective effects of medicinal plants (part 2): plant based review. IOSR Journal of Pharmacy 2016; 6(7): 63-84.

[49] Al-Snafi AE. Beneficial medicinal plants in digestive system disorders (part 2): plant based review. IOSR Journal of Pharmacy 2016; 6(7): 85-92.

[50] Al-Snafi AE. Pharmacology and toxicology of Conium maculatum- A review. The Pharmaceutical and Chemical Journal 2016; 3(2):136-142.

[51] Al-Snafi AE. The constituents and pharmacology of Cnicus benedictus- A review. The Pharmaceutical and Chemical Journal 2016; 3(2):129-135.

[52] Al-Snafi AE. Medicinal importance of Colchicum candidum- A review. The Pharmaceutical and Chemical Journal 2016; 3(2):111-117.

[53] The plant list, Working list of all plant species, http://www.theplantlist.org/tpl/ record/ tro-50149358, http://www.theplantlist.org/tpl/record/tro-28100570, http:// www. theplantlist. org/tpl/record/tro50119437, http://www.theplantlist.org/tpl/ record/kew-2724208

[54] USDA, ARS, National Genetic Resources Program. Germplasm Resources Information Network(GRIN). National Germplasm Resources Laboratory, Beltsville, Maryland. URL: http://www.arsgrin.gov.4/cgi-bin/npgs/html/ taxon.pl?10782 [11 October 2015].

[55] Liu YQ, Heying E and Sherry A. History, global distribution, and nutritional importance of citrus fruits. Comprehensive Reviews in Food Science and Food Safety 2012; 11(6): 530-545.

[56] Scora RW.On the history and origin of citrus. Bulletin of the Torrey Botanical Club 1975;102 (6): 369375.

[57] Srinivasan D, Ramasamy S and Sengottuvelu S. Protective effect of polyherbal formulation on experimentally induced ulcer in rats. Pharmacologyonline 2008; 1: 331-350.

[58] Joy PP, Thomas J, Mathew S and Skaria BP. Medicinal plants. Aromatic and Medicinal Plants Research Station. 1998:189.

[59] Khare CP. Indian medicinal plants: An illustrated dictionary. Springer Publication. 2007: 153-157. Morton J. Orange. In: Fruits of warm climates. Miami, FL 1987: 134-142.

[60] Nadkarni AK. Indian Materia Medica, Vol I, Popular Prakashan, Bombay, 1996: 348.

[61] Peter E, Peter J, Nes B and Asukwo G. Physiochemical properties and fungi toxicity of the essential of Citrus medica L. against groundnut storage fungi. Turk J Bot 2008; 32: 161-164.

[62] Singh VK and Ali ZA. Herbal drugs of Himalaya, Today and tomorrow's Printers and Publishers, New Delhi 1998: 70.

[63] 62-Beatriz AA and Luis RL. Pharmacological properties of citrus and their ancient and medieval uses in the Mediterranean region. J Ethnopharmacol 2005; 97: 89-95.

[64] Clement YN, Morton-Gittens J, Basdeo L, Blades A, Francis MJ, Gomes N, Janjua M and Singh A. Perceived efficacy of herbal remedies by users accessing primary healthcare in Trinidad. BMC Complementary and Alternative Medicine 2007, http://www.biomedcentral.com/1472-6882/7/4

[65] Milind P and Dev C. Orange: range of benefits. IRJP 2012; 3 (7): 59-63.

[66] Manner HI, Buker RS, Smith VE, Ward D and Elevitch CR. Species profile for Pacific island agroforestry. Citrus species (Citrus). www. traditionaltree.org [April 2006] Ver 2.1.

[67] Liogier HA. Descriptive flora of Puerto Rico and adjacent islands, Spermatophyta. Vol. 2. Editorial de la Universidad de Puerto Rico, Río Piedras, PR. 1988: 481.

[68] Little EL Jr and Wadsworth FL. Common trees of Puerto Rico and the Virgin Islands. Agriculture Handbook 249. US Department of Agriculture, Washington, DC. 1964:548.

[69] Okwi DE and Emenike IN. Evaluation of the phytonutrients and vitamins contents of citrus fruits. International J Molecular Medicine and Advance Sciences 2006; 2(1):1-6.

[70] Ferguson U. Citrus fruits processing. Horticultural Science Florida 1990:117-118.

[71] Patil JR. Studies on isolation and characterization of bioactive compounds in lime [Citrus aurantifolia (Christm) Swingle], their antioxidant and anticancer properties. PhD thesis, University of Agricultural Sciences, Dharwad 2009.

[72] Katzer G. Lime [Citrus aurantifolia (Christm. et Panz.) Swengle]. Gernet Katzer's spice pages 2002. http://www-ang.kfunigraz. ac.at/ katzer/engl/ Citr_aur.html.

[73] Colecio-Juárez MC, Rubio-Núñez RE, Botello-Álvarez JE, Martínez-González GM, Navarrete-Bolaños JL and Jiménez-Islas H. Characterization of volatile compounds in the essential oil of sweet lime (Citrus limetta Risso). Chilean Journal of Agricultural Research 2012; 72(2): 275-280.

[74] Huiyan MNL, Begum J, Sardar PK and Rahman MS. Constituents of peel and leaf essential oils of Citrus medica L. J Sci Res 2009; 1 (2): 387-392. 
[75] Gabriele B, Fazio A, Dugo P, Costa R and Mondello L. Essential oil composition of Citrus medica L. Cv. Diamante (Diamante citron) determined after using different extraction methods. J Sep Science 2009; 32: 99-108.

[76] Onyeyirichi I, Ogechi N, Oche O, Jerry U and Gero M. Chemical constituent of Citrus medica limonum leaf essential oil. Journal of Pharmaceutical and Scientific Innovation 2014; 3 (4): 306-309.

[77] Wu Z, Li H, Yang Y, Zhan Y and Tu D. Variation in the components and antioxidant activity of Citrus medica L. var. sarcodactylis essential oils at different stages of maturity. Industrial Crops \& Products 2013; 46: 311-316.

[79] Rowshan V and Najafian S. Headspace analyses of leaf and flower of Citrus limetta (Lemon), Citrus maxima (Pomelo), Citrus sinensis (Orange), and Citrus medica (Cedrum) for volatile compounds by combi-PAL System Technique. Journal of Herbs, Spices \& Medicinal Plants 2013; 19(4): 418-425.

[80] Javed S, Ahmad R, Shahzad K, Nawaz S, Saeed S and Saleem Y. Chemical constituents, antimicrobial and antioxidant activity of essential oil of Citrus limetta var. Mitha (sweet lime) peel in Pakistan. Afr J Microbiol Res 2013; 7(24) 3071-3077.

[81] -Herent MF, De Bie V, Tilquin B. Determination of new retention indices for quick identification of essential oils compounds. Journal of Pharm Biomed Anal 2007; 43: 886-892.

[82] Azar PA, Nekoei M, Larijani K and Bahraminasab S. Chemical composition of the essential oils of Citrus sinensis $\mathrm{cv}$. valencia and a quantitative structure-retention relationship study for the prediction of retention indices by multiple linear regression. J Serb Chem Soc 2011; 76 (12): 1627-1637.

[83] -Okwu DE and Emenike IW. Nutritive value and mineral content of different varieties of citrus fruits. J Food Technology 2007; 5(2); 1054-1092.

[84] Okwu DE.Citrus fruits: A rich source of phytochemicals and their roles in human health. Int J Chem Sci 2008; 6(2): 451-471.

[85] Gattuso G, Barreca D, Gargiulli C, Leuzzi U and Caristi C. Flavonoid composition of citrus juices. Molecules 2007; 12: 1641-1673.

[86] Feng Y, Liang C and Chang LF. Studies on the constituents of Citrus medica L. var. sarcodactylis (Noot.) Swingle. Chinese J Nat Med 2004; 2: 149-151.

[87] Nogata Y, Sakamoto K, Shiratsuchi H, Ishii T, Yano M and Ohta H. Flavonoid composition of fruit tissues of citrus species. Biosci Biotech Biochem 2006; 70: 178-192.

[88] Menichini F. Evaluation of Citrus aurantifolia peel and leaves extracts for their chemical composition, antioxidant and anti-cholinesterase activities. J Sci Food Agric 2002; 92: 2960-2967.

[89] -United States Department of Agriculture, Survey of phenolic compounds produced in citrus, http://www.ars.usda.gov/SP2UserFiles/person/34764/MABSurveyCitrus.pdf [Dec 1998]

[90] Rodríguez-Rivera MP, Lugo-Cervantes E, Winterhalter P and Jerz G. Metabolite profiling of polyphenols in peels of Citrus limetta Risso by combination of preparative high-speed countercurrent chromatography and LC-ESI-MS/MS. Food Chem 2014;158:139-152.

[91] Ezeabara CA, Okeke CU and Aziagba BO. Flavonoid content of Citrus Species grown in Awka, Anambra State, Southeastern Nigeria. Inter J Agri Biosci 2013; 2(3): 103-107.

[92] Ridley BL, O’Neill MA and Mohnen D. Pectins: structure, biosynthesis, and oligo-galacturonide-related signaling. Phytochemistry 2001;57:929-967.

[93] Berhow MA, Hasegawa s and Manners GD (eds.). Citrus limonoids: Functional

[94] chemicals in agriculture and foods. American Chemical Society, Washington DC 2000.

[95] Nour V, Trandafir I and Ionica ME. HPLC Organic acid analysis in different citrus juices under reversed phase conditions. Not Bot Hort Agrobot Cluj 2010; 38 (1): 44-48.

[96] Reddy LJ, Jalli1RD, Jose B and Gopu S. Evaluation of antibacterial \& antioxidant activities of the leaf essential oil \& leaf extracts of Citrus aurantifolia. Asian Journal of Biochemical and Pharmaceutical Research 2012; 2(2): 346-354.

[97] Sekar M. Comparative evaluation of antimicrobial properties of citrus varieties available in Malaysia market. International Journal of Current Pharmaceutical Research 2013; 5(4): 32-35.

[98] Srividhya M, Ramanathan K and Krishnanand N. Efficacy of citrus fruit peel extracts against pathogens causing gastrointestinal disorders. Int J Pharm Pharm Sci 2013; 5(4): 160-163.

[99] Aibinu I, Adenipekun T, Adelowotan T, Ogunsanya T and Odugbemi T. Evaluation of the antimicrobial properties of different parts of Citrus aurantifolia (Lime fruit) as used locally. African Journal of Traditional, Complementary and Alternative medicines (AJTCAM) 2007; 4(2): 185-190.

[100] Pathan RK, Gali PR, Pathan P, Gowtham T and Pasupuleti S. In vitro antimicrobial activity of Citrus aurantifolia and its phytochemical screening. Asian Pacific Journal of Tropical Disease 2012: S328S331.

[101] Yuwanita P. Extraction of citric acid in lime (Citrus aurantifolia) and its potential as an antimicrobial agent for Escherichia coli, Salmonella sp, Lactobacillus acidophilus and Bacillus coagulans. 2011, http://hdl.handle.net/123456789/24845 
[102] Sandoval-Montemayor NE, García A, Elizondo-Treviño E, Garza-González NE, Alvarez L and Camacho-Corona M. Chemical composition of hexane extract of Citrus aurantifolia and AntiMycobacterium tuberculosis activity of some of its constituents. Molecules 2012; 17: 11173-11184.

[103] Tomatake H, Koga T,Yamato M, Kassu A and Ota F. Antibacterial activity of citrus fruit juices against Vibrio species. J Nutr Sci Vitaminol 2006; 52(2):157-160.

[104] de Castillo MC, de Allori CG, de Gutierrez RC, de Saab OA, de Fernandez NP, de Ruiz CS, Holgado AP and de Nader OM. Bactericidal activity of lemon juice and lemon derivatives against Vibrio cholerae. Biol Pharm Bull 2000; 23(10):1235-1238.

[105] Unnisa N, Tabassum H, Ali MN and Ponia K. Evaluation of antibacterial activity of five selected fruits on bacterial wound isolates. Int J Pharm Bio Sci 2012; 3(4): 531 - 546.

[106] Sharma R, Sharma G and Sharma M. Anti-Malassezia furfur activity of essential oils against causal agent of Pityriasis versicolor disease. African Journal of Pharmacy and Pharmacology 2012; 6(13): 979-983.

[107] Dhanavade MJ, Jalkute CB, Ghosh JS and Sonawane KD. Study antimicrobial activity of lemon (Citrus lemon L.) peel extract. British Journal of Pharmacology and Toxicology 2011; 2(3): 119-122.

[108] Hindi NKK and Chabuck ZAG. Antimicrobial activity of different aqueous lemon extracts. Journal of Applied Pharmaceutical Science 2013; 3 (6): 74-78.

[109] Oliveira SA, Zambrana JR, Iorio FB, Pereira CA and Jorge AO. The antimicrobial effects of Citrus limonum and Citrus aurantium essential oils on multi-species biofilms. Braz Oral Res 2014;28:2227.

[110] Shinkafi SA and Ndanusa H. Antibacterial activity of Citrus limon on Acne vulgaris (Pimples). IJSIT 2013; 2(5): 397-409.

[111] Theanphong O, Songsak T and Mingvanish W. Chemical composition and antimicrobial activity of the essestial oil from Citrus medica L. var. sarcodactylis (Sieber) Swingle leaf. Mahidol University Journal of Pharmaceutical Sciences 2008; 35(1-4): 57-61.

[112] Kabra AO, Bairagi GB, Mahamuni AS and Wanare RS. In vitro antimicrobial activity and phytochemical analysis of the peels of Citrus medica L. International Journal of Research in Pharmaceutical and Biomedical Sciences 2012; 3(1): 34-37.

[113] Sah AN, Juyal V and Melkani AB. Antimicrobial activity of six different parts of the plant Citrus medica Linn. Pharmacognosy Journal 2011; 21(3): 80-83.

[114] Menghani E and Sharma SK. Screening for folklore antimicrobial activity. Int J Pharm 2012; $2(3)$ : $557-$ 560.

[115] Kumar RV, Nandini S, and Anitha S. Antityphoid activity of aqueous extract of fruit peel Citrus sinensis. International Journal of Pharma Research and Development 2010; 2(1): 217-221.

[116] Ekwenye UN and Edeha OV. The antibacterial activity of crude extract of Citrus sinensis (sweet orange). International Journal of Pharma and Bio Sciences 2010; 1(4): 742-750.

[117] Lawa D, Bala JA, Aliyu SY and Huguma MA. Phytochemical screening and in vitro anti-bacterial studies of the ethanolic extract of Citrus senensis (Linn.) peel against some clinical bacterial isolates. International Journal of Innovation and Applied Studies 2013; 2(2):138-145.

[118] Khushwaha A, Singh RP, Gupta V and Singh M. Antibacterial properties of peels of citrus fruits. International Journal of Universal Pharmacy and Life Sciences 2012; 2(2): 24-38.

[119] Dhiman A, Nanda A, Ahmad S and Narasimhan B. In vitro antimicrobial status of methanolic extract of Citrus sinensis Linn. fruit peel. Chronicles of Young Scientists 2012; 3(3): 204-208.

[120] Manish K, Mahesh AR and Somashekhar M. Evaluation of antitubercular activity of methanolic extract of Citrus sinensis. International Journal of Pharma Research \& Review 2013; 2(8):18-22.

[121] Rajarajan AT, Vijayasree VG, Kenichi W, Kumar SV, Narasimman G and kumar SS. Anthelmintic and antimicrobial properties of peels of Citrus sinensis. Pharmacologyonline 2009; 1: 363-368.

[122] Hindi NK, Chabuck ZAG and Hindi SKK. Antibacterial evaluation of aqueous extracts of four Citrus species in Hilla. International Journal of Pharmacological Screening Methods 2014; 4(1):43-48.

[123] Amandeep S, Bilal AR and Bevguni A. In vitro antibiotic activity of isolated volatile oil of Citrus sinensis. IJPRD 2009; 7:1-4.

[124] Hussain KA, Tarakji B, Kandy BP, John J, Mathews J, Ramphul V and Divakar DD. Antimicrobial effects of Citrus sinensis peel extracts against periodontopathic bacteria: an in vitro study. Rocz Panstw Zakl Hig 2015; 66(2):173-178.

[125] Bakare AA, Bassey RB, Onyeka CA and Duru FI. Lime Juice (Citrus aurantifolia): Effect on fetal parameters of pregnant Sprague-Dawley rats. International Journal of Medicine and Medical Sciences 2012; 2(5): 114-116.

[126] Ulasli M, Gurses SA, Bayraktar R, Yumrutas O, Oztuzcu S, Igci M, Igci YZ, Cakmak EA and Arslan A. The effects of Nigella sativa (Ns), Anthemis hyalina (Ah) and Citrus sinensis (Cs) extracts on the replication of coronavirus and the expression of TRP genes family. Mol Biol Rep 2014;41(3):1703-1711. 
[127] Kabra AO, Bairagi GB, Mandade RJ and Sakarkar DM. Comparative studies on anthelmintic activity of Citrus medica L. and Ocimum basilicum L. International Journal of Pharmaceutical Sciences Review and Research 2011; 8(1): 6-8.

[128] -Bairagi GB, Kabra AO and Mandade RJ. Anthelmintic activity of Citrus medica L. leaves in Indian adult earthworm. International Journal of PharmTech Research 2011; 3(2):664-667.

[129] 127-Muala BA, Muhii RR and Jaber MA. Effect of the aqueous extract of Citrus medica on protoscolices and Gram positive and Gram negative bacteria in vitro.Al-Nahrain Univ Journal 2008; 11(2): 16-19.

[130] 128-Raj RK. Screening of indigenous plants for anthelmintic action against human Ascaris lumbricoides: Part-II. Indian J Physol Pharmacol 1974;18(2):129-131.

[131] 129-Kumar S, Warikoo R, Mishra M, Seth A and Wahab N. Larvicidal efficacy of the Citrus limetta peel extracts against Indian strains of Anopheles stephensi Liston and Aedes aegypti L. Parasitol Res 2012;111(1):173-178.

[132] -Effiom OE, Avoaja DA and Ohaer, C C. Mosquito repellent activity of phytochemical extracts from peels of Citrus fruit species. Global Journal of Science Frontier Research 2012; 12(1): 1-8.

[133] -Boshtam M, Moshtaghian J, Naderi G, Asgary S and Nayeri H. Antioxidant effects of Citrus aurantifolia (Christm) juice and peel extract on LDL oxidation. J Res Med Sci 2011; 16(7): 951-955.

[134] -Kumari S, Sarmah N and Handique AK. Antioxidant activities of the unripen and ripen Citrus aurantifolia of Assam. International Journal of Innovative Research in Science, Engineering and Technology 2013; 2(9): 4811-4816.

[135] -Shajie D, Wadhwa N, Murthy NBK and Rashmi M. antioxidant efficacy of Citrus limonum pulp and peel- An in vitro study. Drug Invention Today 2013; 5(4): 296-301.

[136] - LML, de Almeida AAC, de Freitas RLM, Cerqueira GS, Saldanha GB, Feitosa CM, and de Freitas RM. Antioxidant and antinociceptive effects of Citrus limon essential oil in mice. J Biomed Biotechnol 2011; doi: 10.1155/2011/678673

[137] -Campêlo LML, Gonçalves FCM, Feitosa CM and Freitas RM. Antioxidant activity of Citrus limon essential oil in mouse hippocampus. Pharm Biol 2011;49:709-715.

[138] -Bertuzzi G, Tirillini B, Angelini P and Venanzoni R. Antioxidative action of Citrus limonum essential oil on skin. European Journal of Medicinal Plants 2013; 3(1): 1-9.

[139] -Hetta MH, El-Alfy TS, Yassin NZ, Abdel-Rahman RF and Kadry EM. Phytochemical and antihyperglycemic studies on Citrus medica l. leaves (Etrog) growing in Egypt. International Journal of Pharmacognosy and Phytochemical Research 2013-14; 5(4); 271-277.

[140] -Sood S, Bansal S, Muthuraman A, Gill NS and Bali M. Therapeutic potential of Citrus medica L peel extract in carrageenan induced inflammatory pain in rat. Res J Med Plant 2009; 3: 123-133.

[141] -Conforti F, Giancarlo AS, Tundis R, Loizzo MR and Menichini F. In vitro activities of Citrus medica L cv. Diamante (Diamante citron) relevant to the treatment of diabetes and Alzheimer's disease. Phytotherapy Research. 2007; 21(5):427-33.

[142] -Kabra AO, Bairagi GB and Wanare RS. K Antidiabetic activity of ethanol extract of Citrus medica L. peels in streptozotocin induced diabetic rats. Journal of Pharmacy Research 2012; 5(3):1287-1289.

[143] -KunduSen S, Saha P, Bhattacharya S, Bala A, Mazumder UK, Gupta M and Haldar PK. Evaluation of in vitro antioxidant of Citrus limmetta and Citrus maxima on reactive oxygen and nitrogen species. Pharmacologyonline 2010; 3: 850-857.

[144] -Mohanty S, Maurya AK, Jyotshna, Saxena A, Shanker K, Pal A and Bawankule DU. Flavonoids rich fraction of Citrus limetta fruit peels reduces proinflammatory cytokine production and attenuates malaria pathogenesis. Curr Pharm Biotechnol 2015;16(6):544-552.

[145] -Vinson JA, Su X, Zubik L and Bose P. Phenol antioxidant quantity and quality in foods: fruits. J Agric Food Chem 2001; 49:5315-5321.

[146] -Gorinstein S, Martin-Belloso O, Park Y, Haruenkit R, Lojek A, Ciz M, Hamidinia A and Jafari M. Comparison of some biochemical characteristics of different citrus fruits. Food Chem 2001; 74:309-315.

[147] -Asjad HMM, Akhtar MS, Bashir S, Din B, Gulzar F, Khalid R and Asad M. Phenol, flavonoid contents and antioxidant activity of six common citrus plants in Pakistan. Journal of Pharmaceutical and Cosmetic Sciences 2013; 1(1):1-5.

[148] -Rekha SS and Bhaskar M. In vtro screening and identification of antioxidant activities of orange (Citrus sinensis) peel extract in different solvents. Int J Pharm Bio Sci 2013; 4(4): (P) 405 - 412

[149] -Al-Ashaal HA and El-Sheltawy ST. Antioxidant capacity of hesperidin from citrus peel using electron spin resonance and cytotoxic activity against human carcinoma cell lines. Pharm Biol 2011; 49(3):276282.

[150] -Pereira-Caro G, Borges G, van der Hooft J, Clifford MN, Del Rio D, Lean ME, Roberts SA, Kellerhals $\mathrm{MB}$ and Crozier A. Orange juice (poly)phenols are highly bioavailable in humans. Am J Clin Nutr 2014;100(5):1378-1384. 
[151] -Kurowska EM and Manthey JA. Hypolipidemic effects and absorption of citrus polymethoxylated flavones in hamsters with diet-induced hypercholesterolemia. J Agric Food Chem 2004; 19: 2879-2886.

[152] -Garg A, Garg S, Zaneveld LJD and Singla A. Chemistry and pharmacology of the citrus bioflavonoid hesperidin. Phytotherapy Research 2001; 15(8): 655-669.

[153] -Ohnishi A, Asayama R, Mogi M, Nakaoka H, Kan-No H, Tsukuda K, Chisaka T, Wang XL, Bai HY, Shan BS, Kukida M, Iwanami J and Horiuchi M. Drinking citrus fruit juice inhibits vascular remodeling in cuff-induced vascular injury mouse model. PLoS One 2015;10(2):e0117616. doi: 10.1371/journal.pone.0117616.

[154] -Akhtar SS. Evaluation of Cardiovascular Effects of Citrus aurantifolia (Linn.) Fruit. Social Science Research Network 2013, http://ssrn.com/abstract=2279447

[155] -Souza A, Lamidi M, Ibrahim B, Samseny A, Mounanga MB and M'Batchi. B.

[156] Antihypertensive effect of an aqueous extract of Citrus aurantifolia (Rutaceae) (Christm.) Swingle, on the arterial blood pressure of mammal. International Research of Pharmacy and Pharmacology 2011; 1(7): 142-148.

[157] -Riaz A, Khan RA, Mirza T, Mustansir T and Ahmed M. In vitro/ in vivo effect of Citrus limon (L. Burm. f.) juice on blood parameters, coagulation and anticoagulation factors in rabbits. Pak J Pharm Sci 2014;27(4):907-915.

[158] -Al-Yahya MA, Mothana RA, Al-Said MS, El-Tahir KE, Al-Sohaibani M and Rafatullah S. Citrus medica "Otroj": Attenuates oxidative stress and cardiac dysrhythmia in isoproterenol-induced cardiomyopathy in rats. Nutrients 2013; 5: 4269-4283.

[159] -Perez YY, Jimenez-Ferrer E, Alonso D, Botello-Amaro CA and Zamilpa A. Citrus limetta leaves extract antagonizes the hypertensive effect of angiotensin II. Journal of Ethnopharmacology 2010; 128(3): 610614.

[160] -Reshef N, Hayari Y, Goren C, Boaz M, Madar Z and Knobler H. Antihypertensive effect of sweetie fruit in patients with stage I hypertension. Am J Hypertens 2005; 18(10): 1360-1363.

[161] -Asgary S and Keshvari M. Effects of Citrus sinensis juice on blood pressure. ARYA Atheroscler 2013; 9(1): 98-101.

[162] -Kumamoto H, Matsubara Y, Izuka Y, Okamoto K, Yokoi K. Structure and hypotensive effect of flavonoid glycosides in orange (Citrus sinensis OSBECK) peelings. Agric Biol Chemistry 1986; 50: 781 783.

[163] -Yaghmaie P, Parivar K and Haftsavar M. Effects of Citrus aurantifolia peel essential oil on serum cholesterol levels in Wistar rats. Journal of Paramedical Sciences (JPS) 2011; 2(1):29-32.

[164] -Akinboyewa OM. Effect of Citrus aurantifolia on hepatic lipidomics in female albino rats. BSc thesis, Department of Biochemistry, College of Natural Sciences, Federal University of Agriculture, Abeokuta 2012.

[165] -Hiramitsu M, Shimada Y, Kuroyanagi J, Inoue T, Katagiri T, Zang L, Nishimura Y, Nishimura N and Tanaka T. Eriocitrin ameliorates diet-induced hepatic steatosis with activation of mitochondrial biogenesis. Sci Rep 2014; 4: 3708.

[166] -Menichini F, Tundis R, Loizzo MR, Bonesi M, Liu B, Jones P, Persaud SJ, Mastellone V, Lombardi P, Houghton PJ, Avallone L and Menichini F. C. medica cv Diamante peel chemical composition and influence on glucose homeostasis and metabolic parameters. Food Chemistry 2011; 124(3): 1083-1089.

[167] -Potter JD. Vegetables, fruit, and cancer. Lancet 2005;366:527-530.

[168] -Gharagozloo M, Doroudchi M and Ghaderi A. Effects of Citrus aurantifolia concentrated extract on the spontaneous proliferation of MDA-MB-453 and RPMI-8866 tumor cell linesmore. Phytomedicine 2002; 9: 475-477.

[169] -Patil JP, Jayaprakasha GK, Murthy KNC, Tichy EE, Chetti MB and Patil BS. Apoptosis-mediated proliferation inhibition of human colon cancer cells by volatile principles of Citrus aurantifolia. Food Chemistry 2009; 114:1351-1358.

[170] -Addul Redha WA, Yaseen NY and Gali MA. Genotoxic effects of Citrus limon (L.) Burm. f. on human lymphocytes. Iraqi Journal of Cancer and Medical Genetics 2012; 5(1): 97-107.

[171] 168-Entezari M, Majd A, Falahian F, Mehrabian S, Hashemi M and Lajimi AA. Antimutagenicity and anticancer effects of Citrus medica fruit Juice. Acta Medica Iranica 2009; 47(5): 373-377.

[172] - Mazaki M, Ishii T and Uyeta M. Mutagenicity of hydrolysates of citrus fruit juices. Mutat Res 1982;101(4):283-291

[173] -Quignard ELJ. Screening of plants found in Amazonas state for lethality towards

[174] brine shrimp. Acta Amazonica 2003;33:93-104.

[175] -KunduSen S, Bala A, Kar B, Bhattacharya S, Mazumder UK, Gupta M and Haldar PK. Antitumor potential of Citrus limetta fruit peel in Ehrlich ascites carcinoma bearing Swiss albino mice. Alternative Medicine Studies 2012; 2(e10):48-51. 
[176] -Tanaka Y, Makita H, Kawabata K, Mori H, Kakumoto M, Satoh K, Hara A, Sumida T, Fukutani K, Tanaka $\mathrm{T}$ and Ogawa $\mathrm{H}$. Modulation of N-methyl-N-nitrosamine-induced rat oesophageal tumorigenesis by dietary feeding of diosmin and hesperidin, both alone and in combination. Carcinogenesis. Agricultural and Food Chemistry 1997; 18: 761-769.

[177] -Tanaka Y, Makita H, Kawabata K, Mori H, Kakumoto M, Satoh K, Hara A, Sumida T, Fukutani K, Tanaka $\mathrm{T}$ and Ogawa H. Chemoprevention of azoxymethane-induced rat colon carcinogenesis by the naturally occurring flavonoids, diosmin and hesperidin. Carcinogenesis 1997; 18:957-965.

[178] -Jacob R, Hasegawa S and Gary Manners. The potential of Citrus limonoids as anticancer agents. Perishables Handling Quarterly 2000; 102: 6-8.

[179] 175-Brooker DJR, Snape M, Johnson E, Ward D and Payne M. Single case evaluation of the effects of aromatherapy and massage on disturbed behaviour in severe dementia. Brit J Clin Psychol 1997; 36: $287-$ 296.

[180] -Wolfe N and Herzberg J. The study protocol of a blinded randomized-controlled cross-over trial of lavender oil as a treatment of behavioural symptoms in dementia. Int J Geriatr Psychiatry 1996; 11: 926 927.

[181] -Campêlo LML, Gonçalves FCM, Feitosa CM and Freitas RM. Evaluation of central nervous system effects of Citrus limon essential oil in mice. Revista Brasileira de Farmacognosia (Brazilian Journal of Pharmacognosy) 2011; 21(4):668-673.

[182] -Li R, Wang X, Qin T, Qu R and Ma S. Apigenin ameliorates chronic mild stress-induced depressive behavior by inhibiting interleukin-1 $\beta$ production and NLRP3 inflammasome activation in the rat brain. Behav Brain Res 2015;296:318-325.

[183] 179-de Oliveira FR, Cerqueira Gs, de Freitas RLM, Júnior JSC, Feitosa CM and de Freitas RM. Anxiolytic- and antidepressant-like effects of the ethanolic extract from Citrus limon plant widely used in Northeastern Brazil . African Journal of Pharmacy and Pharmacology 2013; 7(30): 2173-2179.

[184] -Riaz A, Khan RA and Algahtani HA. Memory boosting effect of Citrus limon, Pomegranate and their combinations. Pak J Pharm Sci 2014;27(6):1837-1840.

[185] -Lopes C, Gonçalves eSá C, de Almeida AA, da Costa JP, Marques TH, Feitosa CM, Saldanha GB and de Freitas RM. Sedative, anxiolytic and antidepressant activities of Citrus limon (Burn) essential oil in mice. Pharmazie 2011;66(8):623-627.

[186] -Khan RA and Riaz A. Behavioral effects of Citrus limon in rats. Metab Brain Dis 2015; 30(2):589-596.

[187] -Huang CY, Kuo WW, Shibu MA, Hsueh MF, Chen YS, Tsai FJ, Yao CH, Lin CC, Pan LF and Ju DT. Citrus medica var. sarcodactylis (Foshou) activates fibroblast growth factor-2 signaling to induce migration of RSC96 Schwann cells. Am J Chin Med 2014; 42(2): 443-452.

[188] -Faturi CB, Leite JR, Alves PB, Canton AC and Teixeira-Silva F. Anxiolyticlike effect of sweet orange aroma in Wistar rats. Prog Neuropsychopharmacol Biol Psychiatry 2010;34(4):605-609.

[197] -Akhila S, Bindu AR, Bindu K and Aleykutty NA. Phytochemical and pharmacological evaluation of Citrus limon pell. World Journal of Pharmacy and Pharmaceutical Sciences 2015; 4(3): 1128-1135.

[198] -Ahmad M, Ansari MN, Alam A and Khan TH. Oral dose of citrus peel extracts promotes wound repair in diabetic rats. Pak J Biol Sci 2013;16(20):1086-1094.

[199] -Sah AN, Josh A, Juyal V and Kumar T. Antidiabetic and hypolipidemic activity of Citrus medica Linn. seed extract in streptozotocin induced diabetic rats. Pharmacognosy Journal 2011; 3(23): 80-84.

[200] -Peng CH, Ker YB, Weng CF, Peng CC, Huang CN, Lin LY and Peng RY. Insulin secretagogue bioactivity of finger citron fruit (Citrus medica L. var. Sarcodactylis Hort, Rutaceae). J Agric Food Chem 2009;57(19):8812-8819.

[201] -KunduSen S, Haldar PK, Gupta M, Mazumder UK, Saha P, Bala A, Bhattacharya S and Kar B. Evaluation of antihyperglycemic activity of Citrus limetta fruit peel in streptozotocin-induced diabetic rats. ISRN Endocrinol 2011; doi: 10.5402/2011/ 869273.

[202] -Padilla-Camberos E, Lazcano-Díaz E, Flores-Fernandez JM, Owolabi MS, Allen K and VillanuevaRodríguez S. Evaluation of the inhibition of carbohydrate hydrolyzing enzymes, the antioxidant activity, and the polyphenolic content of Citrus limetta peel extract. Scientific World Journal 2014; 2014: 121760. doi: 10.1155/ 2014/121760.

[203] -Parmar HS and Kar A. Medicinal values of fruit peels from Citrus sinensis, Punica granatum and Musa paradisiacal with respect to alterations in tissue lipid peroxidation and serum concentration of glucose, insulin and thyroid hormones. J Med Food 2008; 11: 376-381.

[204] -Parmar HS and Kar A. Possible amelioration of atherogenic diet induced dyslipidemia, hypothyroidism and hyperglycemia by the peel extracts of Mangifera indica, Cucumis melo and Citrullus vulgaris fruits in rats and liver antioxidative enzyme avtivity in rats. Biosci Biotect Biochem 1995; 59: 595-601.

[205] -Parmar HS and Kar A. Antidiabetic potential of Citrus sinensis and Punica granatum peel extracts in alloxan treated male mice. Biofactors 2007;31(1):17-24. 
[206] -Chen CH, Sheu MT, Chen TF, Wang YC, Hou WC, Liu DZ, Chung TC and Liang YC. Suppression of endotoxin-induced proinflammatory responses by citrus pectin through blocking LPS signaling pathways.Biochemical Pharmacology 2006; 7(2): 1001-1009.

[207] -Bairagi GB, Kabra AO and Mandade RJ. Anti-nociceptive activity of an ethanolic extract of Citrus limon L. (Burm) Peels. Journal of Pharmacy Research 2011; 4(5): 1410-1411.

[208] -Yi CY, Hao LC, Chiang SY and Shung WUT. Anti-inflammatory principles from the stem and root barks of Citrus medica. Chem Pharmaceut Bull 2010; 58, 61-65.

[209] -Archana NS, Vijay J and Melkani AB. Analgesic activity of fruit decoction of Citrus medica Linn. Journal of Pharmacy Research 2010; 3(9):2119-2121.

[210] -KunduSen S, Gupta M, Mazumder UK, Haldar PK, Saha P, Bhattacharya S, Naskar S and Panda Sp. Exploration of anti-inflammatory potential of Citrus limetta Risso and Citrus maxima ( J. Burm.) MERR. Pharmacologyonline 2011; 1: 702-709.

[211] 199-Cerletti C, Gianfagna F, Tamburrelli C, De Curtis A, D'Imperio M, Coletta W, Giordano L, Lorenzet R, Rapisarda P, Reforgiato Recupero G, Rotilio D, Iacoviello L, de Gaetano G and Donati MB. Orange juice intake during a fatty meal consumption reduces the postprandial low-grade inflammatory response in healthy subjects. Thromb Res 2015;135(2):255-259.

[212] 200-Yoshizaki N, Fujii T, Masaki H, Okubo T, Shimada K and Hashizume R. Orange peel extract, containing high levels of polymethoxy flavonoid, suppressed UVB-induced COX-2 expression and PGE2 production in HaCaT cells through PPAR- $\gamma$ activation. Exp Dermatol 2014;23 Suppl 1:18-22.

[213] -Kulkarni TR, Mateenuddin M, Bodhankar SL and Saharabudhe RA. Reversible anti- fertility effect of lemon seeds (Citrus limonum) in male albino rats. International Journal of Research in Pharmaceutical and Biomedical Sciences 2012; 3(2): 545-550.

[214] -Kulkarni TR, Kothekar MA and Mateenuddin M. Study of anti- fertility effect of lemon seeds (Citrus limonum) in female albino mice. Indian J Physiol Pharmacol 2005; 49 (3) : 305-312.

[215] -Kulkarni TR, Mateenuddin M, Sahasrabudhe RA and Pandit VA. Estrogenic activity of alcoholic extract of lemon seeds (Citrus limonum ) on immature albino rats. International Journal of Research in Pharmaceutical and Biomedical Sciences 2012; 3(3):1231-1235.

[216] -Kachroo M and Agrawal SS. Anti-implantation activity of different extract of the peels of Citrus medica, Linn. Int J PharmTech Res 2011; 3(1); 535-539.

[217] -Patil SJ, Banagar SR, Banagar RR, Venkatesh S, Vishwanatha T and Patil1 SP. Withdrawal antifertility effect of petroleum ether extract of Citrus medica seeds in female albino rats. Medicinal Plants 2013; 5(2): 75-81.

[218] -Patil SJ and Patil SB. Efficacy of Citrus medica seeds extracts on reproductive activities in female albino rats. Pharmacologyonline 2009; 2: 803-817.

[219] -Patil SBS. Estrogenic activity of petroleum ether extract of Citrus medica L on immature albino rats. Int J Green Pharm 2007; 2: 91-94.

[220] -El-Alfy TS, Hetta MH, Yassin NZ, Abdel Rahman RF and Kadry EM. Estrogenic activity of Citrus medica L leaves growing in Egypt. Journal of Applied Pharmaceutical Science 2012; 2 (8):180-185.

[221] -Nagaraju B, Anand SC, Ahmed N, Chandra JN, Ahmed F and Padmavathi GV. Antiulcer activity of aqueous extract of Citrus medica Linn. fruit against ethanol-induced ulcer in rats. Advances in Biological Research 2012; 6 (1): 24-29.

[222] -Cook DG, Carey IM, Whincup PH, Papacosta O, Chirico S, Bruckdorfer KR and Walker M. Effect of fresh fruit consumption on lung function and wheeze in children. Thorax 1997; 52: 628-633.

[223] - Forastiere F, Pistelli R, Sestini P, Fortes C, Renzoni E, Rusconi F, Dell'Orco V, Ciccone G, and Bisanti L. Consumption of fresh fruit rich in vitamin $\mathrm{C}$ and wheezing symptoms in children. Thorax 2000; 55(3): 283-288.

[224] -Bolhari B, Sharifian MR, Aminsobhani M, Esfehani HRM and Tavakolian P. Assessing the efficacy of Citrus aurantifolia extract on smear layer removal with scanning electron microscope. Iranian Endodontic Journal 2012;7(2): 88-97.

[225] -Gründemann C, Papagiannopoulos M, Lamy E, Mersch-Sundermann $\quad V \quad$ and Huber $R$. Immunomodulatory properties of a lemon-quince preparation (Gencydo®) as an indicator of anti-allergic potency. Phytomedicine 2011; 18(8-9):760-768.

[226] -Baars EW, Jong MC, Boers I, Nierop AFM and Savelkoul HFJ. A comparative in vitro study of the effects of separate and combined products of Citrus e fructibus and Cydonia e fructibus on immunological parameters of seasonal allergic rhinitis. Mediators of Inflammation 2012 : 1-10, doi:10.1155/2012/109829

[227] -Huber R, Stintzing FC, Briemle D, Beckmann C, Meyer U and Gründemann C. In vitro antiallergic effects of aqueous fermented preparations from Citrus and Cydonia fruits. Planta Med 2012;78(4):334340. 
[228] -Baars EW, Jong M, Nierop AFM, Boers I and Savelkoul FHJ. Citrus/Cydonia compositum subcutaneous injections versus nasal spray for seasonal allergic rhinitis: A randomized controlled trial on efficacy and afety. ISRN Allergy 2011; doi:10. 5402/2011/836051

[229] -Asnaashari S, Delazar A, Habibi B, Vasfi R, Nahar L, Hamedeyazdan S and Sarker SD. Essential oil from Citrus aurantifolia prevents ketotifen induced weight-gain in mice. Phytotherapy Research 2010; 24(12): 1893, DOI : 10.1002/ptr.3227

[230] -Shalaby NMM, Abd-Alla HI, Ahmed HH and Basoudan N. Protective effect of Citrus sinensis and Citrus aurantifolia against osteoporosis and their phytochemical constituents. Journal of Medicinal Plants Research 2011; 5(4): 579-588.

[231] -Muthiah PL. In vitro xanthine oxidase inhibitory activity of leaves, fruits and peel extract of Citrus aurantium, Citrus limetta, and Citrus limon. International Journal of Phytopharmacy 2012; 2 (3):77-80.

[232] -Honow R, Laube N, Schneider A, Kessler T and Hesse A. Influence of grapefruit, orange, and applejuice consumption on urinary variables and risk of crystallization. Br J Nutr 2003; 90: 295-300.

[233] -Hon FM, Oluremi OIA and Anugwa FOI. The effect of dried sweet orange (Citrus sinensis) fruit pulp meal on the growth performance of rabbits. Pakistan Journal of Nutrition 2009; 8 (8): 1150-1155.

[234] -Peixoto JS, Comar JF, Moreira CT, Soares AA, de Oliveira AL, Bracht A and

[235] Peralta RM. Effects of Citrus aurantium (Bitter Orange) fruit extracts and $p$-synephrine on metabolic fluxes in the rat liver. Molecules 2012; 17: 5854-5869.

[236] -Shanmugam PST, Venkataraman S and Ariamuthu S. Cytoprotective activity of Citrus aurantifolia fruits extract against aflatoxin-B1 induced cytotoxicity. Int J Res Pharmacology Pharmacotherapy 2013; 2(2): 408-413.

[237] -Bhavsar SK, Joshi P, Shah MB and Santani DD. Investigation into hepato-protective activity of Citrus limon. Pharmaceutical Biology 2007; 45(4): 303-311.

[238] -Chavada Kalpeshisinh S, Fadadu Kumar N, Patel Kirti N, Patel Kalpana G and Gandhi Tejal R. Effect of flavonoid rich fraction of Citrus medica Linn. on ethylene glycol induced urolithiasis in rats. J Drug Deli Therap 2012; 2 (4): 109-116.

[239] -Mehmet K, Fatma I, Hasan A, Aydın H, Mehmet T and Hanefi O. Evaluation of hepatoprotective activity of Bergamot orange in rats. Eastern Journal of Medicine 2005;10:1-4.

[240] -Selected plant substances in natural cosmetics. Survey of chemical compounds in consumer products. Survey no. 11-2002, http://eng.mst.dk/media/mst/67490/Survey\%20no. \% 2011-UK.pdf

[241] -Chunlaratthanaphorn S, Lertprasertsuke N, Srisawat U, Thuppia A, Ngamjariyawat A, Suwanlikhid $\mathrm{N}$ and Jaijoy K. Acute and subchronic toxicity study of the water extract from root of Citrus aurantifolia (Christm. et Panz.) Swingle in rats. Songklanakarin J Sci Technol 2007; 29(1): 125-139.

[242] -Arbo MD, Schmitt GC, Limberger MF, Charao MF, Moro AM, Ribeiro GL, Dallegrave E, Garcia SC, Leal MB and Limberger RP. Subchronic toxicity of Citrus aurantium L. (Rutaceae) extract and psynephrine in mice. Regulatory Toxicology and Pharmacology 2009; 54: 114-117.

[243] -Jänicke C, Grünwald J and Brendler T. Handbuch Phytotherapie - Indikationen-AnwendungenWirksamkeit-Präparate. Wiss, Verlagsgesell, Stuttgart 2003.

[244] -Mishra AK, Kishori N, Dubey NK and Chansouria JPN. An evaluation of the toxicity of the oil of Cymbopogon citrates and Citrus medica in rats. Phytotherapy Res 1992; 6:279-281.

[245] -Jänicke C, Grünwald J and Brendler Th. "Handbuch Phytotherapie - Indikationen -AnwendungenWirksamkeit-Präparate. Wiss Verlagsgesell. Stuttgart 2003. 183-HSDB- Oil of orange - CAS no. 8008$57-9$ 